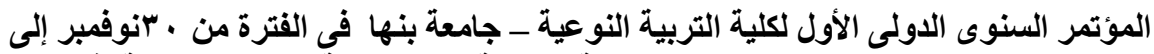

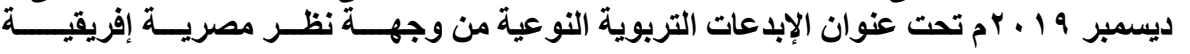

\title{
Effect of Red Grape Juice and Kiwi Juice on Re- duction of Potato Chips Hazards in Experimental Rats.
}

\section{Tasneem Sobhy Fahmy and Marwa Ezz El-Din Ibrahim}

Nutrition and Food Science Department, Faculty of Home Economics Helwan University

\section{Abstract}

Nowadays, it is common and easy to eat unhealthy food especially potato chips which poor nutritional value, low micronutrients and high content of fats and calories. This study carried out to investigate the effect of dietary supplementation with red grape juice and kiwi juice on reduction of potato chips hazards in experimental rats. It's known, the red grape Juice and kiwi juice are rich in polyphenols and antioxidant activity. Forty two adult male albino rats weighing $(10 \cdot \pm 0 \mathrm{~g}$.) were randomly distributed after adaptation period into 7 main groups ( $\vee$ of each). The first main group $(n=V)$ was as a negative control group (-ve) and fed on basel diet. Group $r$ rats fed on basel diet supplemented with potato chips $r \cdot \%$ as a positive control group (+ve). Group $r$ and $\varepsilon$ fed on basel diet supplemented with potato chips $r . \%$ and administrated orally with $\bullet$ and 1. ml grape juice for ${ }^{\top}$ weeks, respectively. Group ${ }^{\bullet}$ and $\boldsymbol{\gamma}$ fed on basel diet supplemented with potato chips $r . \%$ and administrated orally with $\bullet$ and $1 \cdot \mathrm{ml}$ kiwi juice for 9 weeks, respectively. At the end of the experimental period ( $\$$ weeks) blood samples was taken for biochemical analyses. Feed intake and body weight gain were estimated and calculated. In addition, the activities of alanine transaminase (ALT), aspartate transaminase (AST), urea nitrogen, creatinine , lipid profile, antioxidants enzymes, MDA as well as hematological profile were analyzed. Histobathological examination liver and kidneys were done. The results showed that liver enzymes such as alanine transaminase (ALT), aspartate aminotransferase (AST), urea nitrogen and criatinine were decreased significantly in the groups $\Psi, \&, \diamond$, and $\uparrow$, respectively compared with the pos- 


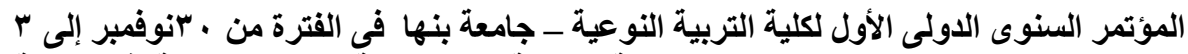

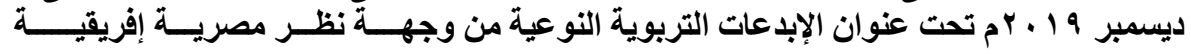

itive control group. In addition MDA were decreased significantly in the groups $r,\{, \bullet$, and $₹$, respectively compared with the positive control group. However, lipid profile such as total cholesterol, tri glyceride, LDL, VLDL was decreased significantly when compared with positive control group. However hematological profile in addition HDL and antioxidant enzymes (CAT and SOD) were significantly increased in groups $\uparrow,\{, \bullet$, and $\uparrow$, respectively compared with the positive control group. Oral administration of red grape juice and kiwi juice at deferent levels reduced potato chips hazards. So, the present study revealed that frequent consumption of potato chips caused a lot of harmful effects of health but the regular consumption of grape juice and kiwi juice have an important role in reduction these hazardous effects.

Key words: Red grape, Kiwi fruit, Liver functions, Hematological parameters, Lipid profile, Rats, Antioxidant enzymes, Histopathology.

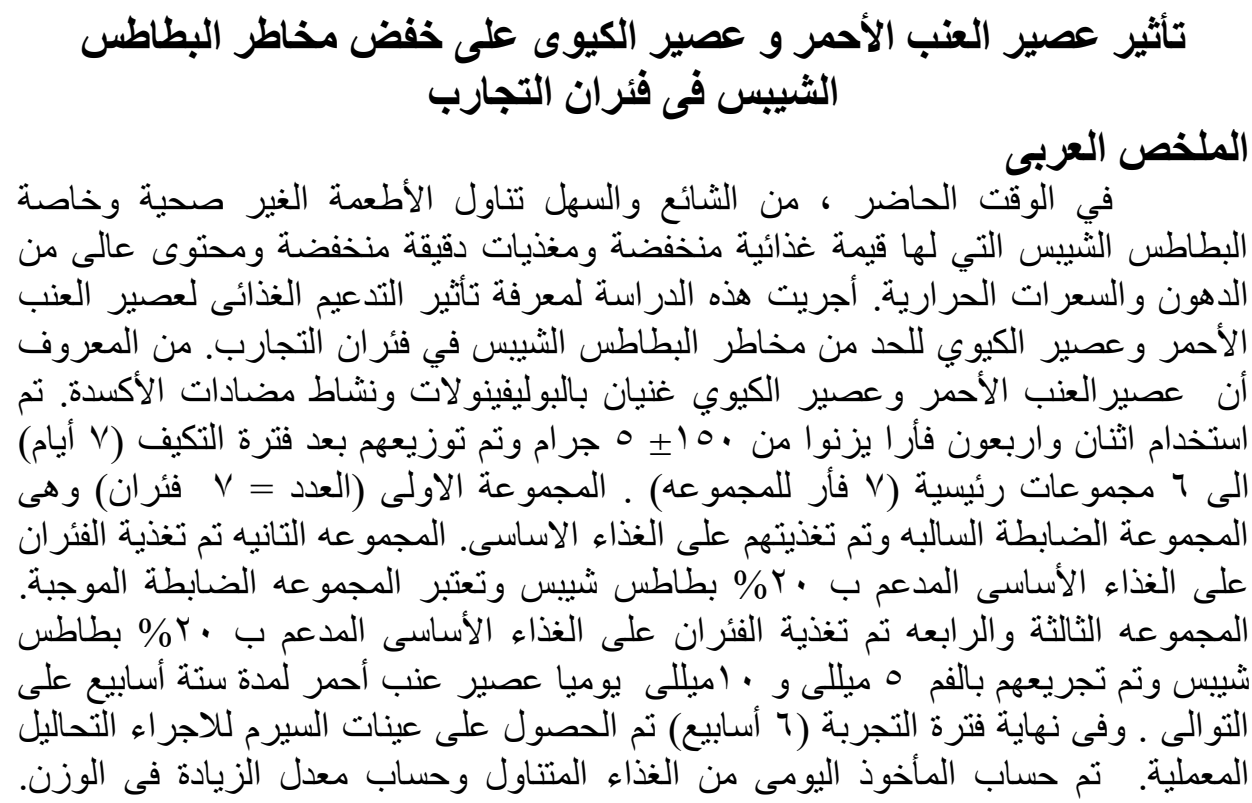




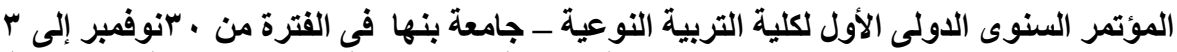

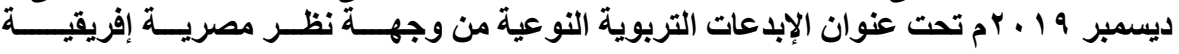

بالإضافة الى , تم تقدير ALT AST ونبتروجين اليوريا , الكرياتينين, دهون الدم ,مضادات

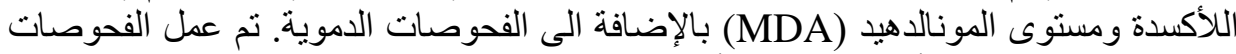

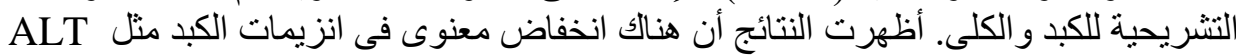

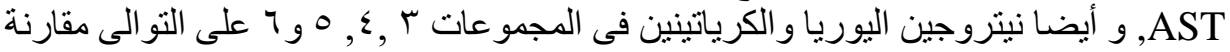

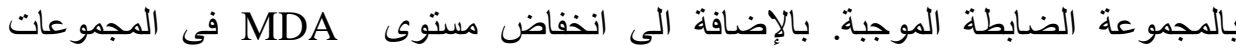

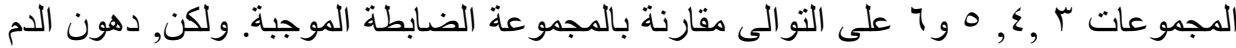

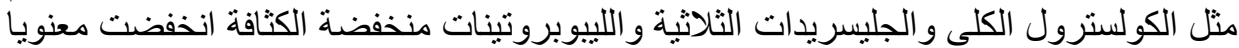

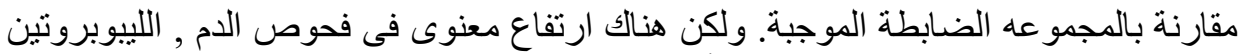

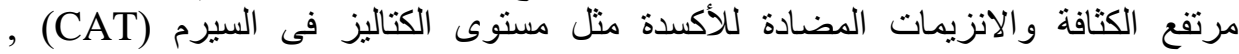

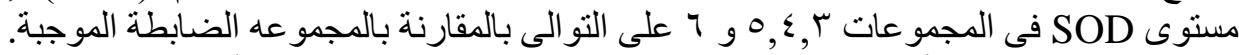

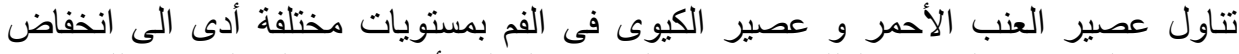

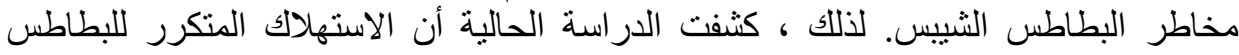

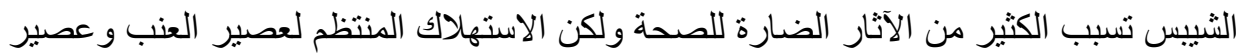

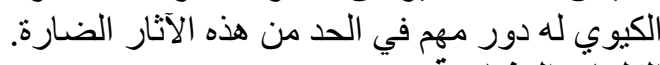

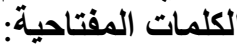

العنب الأحمر , فاكهة الكيوى , وظائف الكبد, فحوصات الدح, دهون الدح, الفئران, مضادات الاكسده و الفحوص التشريحية.

\section{Introduction}

Potato chips are a common snack in the world it is typically high in fat and calories, which can raise the risk of weight gain, dyslipidemia, decrease the hemoglobin and other of hematological profile in addition obesity. Weight gain associated with potato chips intake is a common reason of a lot of health problems such as hypertension, hyperlipidemia, diabetes mellitus (Duran et al., r... y).

One potential mechanism that could explain the health problems of potato chips is the high glycemic load. Glycemic load is a measurement that reflects how a serving of a specific food affects glucose concentrations in the human body. The postprandial hyperglycemia that follows a high glycemic load meal has been associated with endothelial dysfunction, oxidative stress, and inflammation, all potentially important mechanisms in the development of hypertension (Ceriello et al., 1991, Title et al., r... and Ludwig, r.. r). 


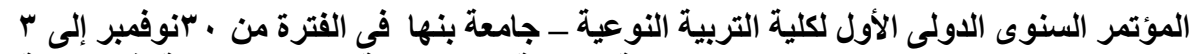

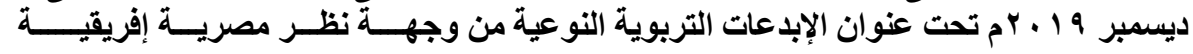

Frequent potato chips consumption can contribute to high cholesterol levels because of the amount and type of fat found in chips. Most chips are deep-fried, a process that creates trans fats, the most harmful type. Also, the oils used for frying chips are often saturated fats, which also contribute to high cholesterol levels. High levels of trans fat in the diet are correlated to high levels in the blood. High levels of trans fats in the bloodstream are associated with high levels of LDL cholesterol and an increased risk of coronary heart disease. In addition, high intake of sodium in potato chips can cause an increase in blood pressure, which can lead to stroke, heart failure, coronary heart disease (Stanley, r.. V).

Healthful products from fruit have obtained considerable attention in recent years for their diverse pharmacological properties, including antioxidants (Takeoka and Dao,..$+ M$ ). Red grape are a rich source of nutrients and phytochemicals, red grape contains many saponins, alkaloids, flavonoids and steroids. It is a natural antioxidant as a result of occurrence of glutathione.

Red grape contain a variety of antioxidants and polyphenols. Antioxidants neutralize harmful free radicals to help prevent the process of oxidation that damages cells but in fact, neutralizing free radicals happens naturally if we eat foods like grapes that promote antioxidant activity. When free radicals are left to their own devices, a condition called "oxidative stress" occurs. Oxidative stress is now associated with numerous health conditions and chronic illnesses. Red grapes are an excellent source of vitamin $\mathrm{K}$, which plays a key role in helping blood to clot in order to prevent excessive bleeding and may also be important in bone health. Grapes contain $\vee \%$ of the recommended daily intake of potassium (Imran et el., r. IV).

Red grapes and its juices are the major source of dietary resveratrol in humans and have both chemo-preventive and therapeutic properties against various diseases. Also, red grape have numerous implications for human health. Red grape has been useful for reducing the extent of diabetes mellitus, digestive problems and cardiovascular disorders. The 


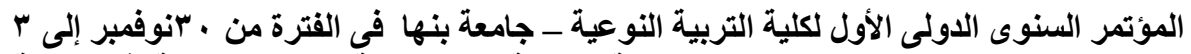

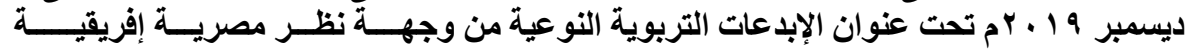

review elaborates the health claims of various chemical components of grapes and their functional roles, with special reference to antioxidant potential, immune-nutrition, anticancer perspectives and cardiovascular cure (Imran et el., r.IV).

Kiwi fruit can be described as nutritious, providing an excellent source of vitamin $\mathrm{C}$ and a good source of folate and potassium (Ferguson A. and Ferguson L., r.. M). One fruit provides approximately 1.\% of the recommended daily requirement of dietary fiber. The dietary fiber in kiwi can also provide heart benefits by lowering the triglycerides. The vitamin $\mathrm{K}$ in kiwi also promotes healthier, stronger bones (Denise et al., r. Ir).

Kiwi also contains vitamin $\mathrm{E}$ and a range of phytochemicals and carotenoids that might also be beneficial to health. Kiwi contains Phytochemicals which including beta-carotene, lutein, anthocyanins, and ellagic acid. These phytochemicals reduce the risk of heart disease, certain types of cancer, cataracts, and macular degeneration (kopparapu, r. 1 ' and Pincemail et al., $r \cdot(1)$. In addition, Kiwifruit had the strongest antioxidant effects which may prevent the development and deterioration of diseases caused by oxidative stress. Kiwi fruit can be made a delicious part of every meal; they can be eaten fresh as a snack, or as a part of a meal or cooked (Iwasawa et al., r. 11 and Donno et al., r. 1 r).

\section{Aim of the study}

This study was conducted to evaluate the effect of red grape juice and Kiwi juice at two different levels $\left({ }^{\circ}\right.$ and $\left.1 \cdot \mathrm{ml}\right)$ to reduced potato chips hazards.

\section{Materials and methods}

\section{Materials:}

Fruit: The mature fresh red grape and kiwi were purchased from local markets in Egypt and identified by Department of Taxonomy, Faculty of Science, Cairo University. 


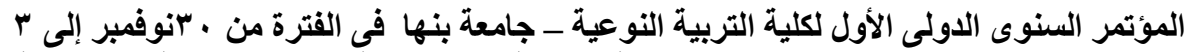

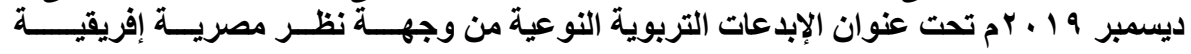

Rats: Forty two adult male albino rats of Sprague Dawley strain, weighing $\left(\mathcal{C}^{\circ} \cdot \pm^{\circ} \mathrm{g}\right.$.) were purchased from Helwan Farm for Experimental Animals, Cairo, Egypt.

Chemicals: Kits for biochemical analysis were purchased from Biodiagnostic Company for Pharmaceutical and chemicals, Dokki, Egypt. Casein, vitamins, minerals, cellulose, starch, and choline were obtained from Morgan Chemical Factory, Cairo, Egypt.

\section{Methods:}

\section{Preparation of Red grape juice and Kiwi juice:}

The fresh red grape fruits and Kiwi fruits were washed by using tap water to remove possible potential pathogenic microorganisms and dust, then prepared by mixing $\Lambda \cdot$ g of red grape or kiwi fruit pulp with $r \cdot \mathrm{ml}$ water using electric blender.

\section{Determination of Phenolic Compounds:}

Phenolic compounds were determination by HPLC according to the method of Goupy et al., ( 199 q)

\section{Determination of Antioxidant Activity and Total Carote- noid:}

Antioxidant activity and total carotenoid were determined according to the methods described by Politeo et al., $(\Gamma \ldots \downarrow)$ and Horwitz and Latimer, $(r . . v)$.

\section{Experimental Animal Design:}

Forty two adult male rats of Sprague Dawley strain weighing $10 . \pm{ }^{\circ} \mathrm{g}$ body weight used in this study. The rats were purchased from the Laboratory Animal Colony, Helwan, Egypt. The animals were housed under hygienic conditions at a room temperature of $r^{\circ} \pm r^{\circ} \mathrm{C}$ with moderate humidity of $0 \cdot-7 . \%$ in the Animal House of Agricultural Research Center, Giza, Egypt. Basal diet and water were allowed ad libitum. 


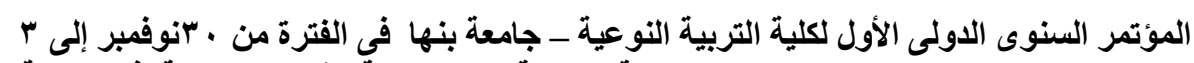

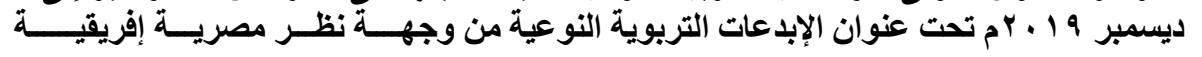

\section{Preparation of Basal Diet:}

Basal diet was prepared according to Reeves et al. ( $19 q \%)$. It consists of $\uparrow$. $\%$ protein, $1 . \%$ sucrose, $₹ . \vee \%$ corn oil, $\uparrow \%$ choline chloride, $1 \%$ vitamin mixture, $\uparrow . \diamond \%$ salt mixture and $\diamond \%$ fibers. The remainder was corn starch up to $1 . . \%$.

Animals were divided into six main groups $(n=\vee$, once). The first main group $(n=\vee)$ were fed on the basal diet during the experimental period as a negative control group (-ve). The second main group rats fed on basel diet supplemented with $r . \%$ potato chips as a positive control group (+ve). Group $r$ and $\varepsilon$ rats fed on basel diet supplemented with $r . \%$ potato chips in the same time by oral gavage $\bullet$ and $1 \cdot \mathrm{ml}$ from $\wedge . \%$ water red grape Juice, respectively. Group ${ }^{\circ}, 1$ rats fed on basel diet supplemented with $r . \%$ potato chips in the same time by oral gavage ${ }^{\circ}$ and $1 \cdot \mathrm{ml}$ from $\wedge . \%$ water kiwifruite Juice, respectively.

At the end of the experiment ('weeks) all rats fasted over-night, lightly anesthetized under ether. Blood was withdrawn into clean dry centrifuge plastic tubes. Blood samples were centrifuged and serum were obtained then stored at $-r \cdot{ }^{\circ} \mathrm{C}$ in a clean well stopped vial until analysis.

\section{Biochemical Analysis:}

\section{Determination of Serum Liver Enzymes:}

The enzyme alanine amino transeferase (ALT) was determined in serum to the method of Sherwin (191 s). The enzyme aspartate amino transeferase (AST) was determined according to Young ( $19 q \circ)$.

\section{Determination of Serum Kidney Functions:}

Serum urea nitrogen concentration was determined by the method $\cdot \mathrm{f}$ Fossati et al., (191.). However, Creatinine was determined according to the method described by Henry ( $9 \mathrm{~V} \varepsilon$ ).

\section{Determination of Serum Malondialdehyde:}

Serum malondialdehyde (MDA) was determined according of Draper and Hadly, ( $199 \cdot)$. 


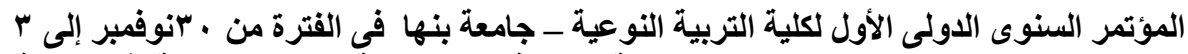

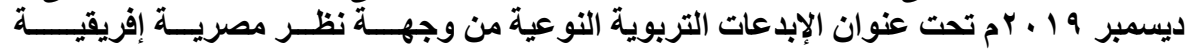

Determination of Catalase (CAT):

Serum CAT activity was measured in tissue homogenate according to Aebi ( 191 \&).

\section{Determination of Superoxide Dismutase (SOD):}

Serum SOD activity was measured according to Nishikimi et al., (19Vr).

\section{Determination of Lipid Profile:}

Total cholesterol in the serum was determined according to the method described by Allain et al., ( $9 \vee \boldsymbol{\xi})$. Triglycerides were determined according to the method described by Fossati and Principe, ( $191 \mathrm{r})$. HDL was determined by the method of Lopesvirell et al., ( $19 V y$ ). The concentration of low density lipoprotein (LDL) and very low density lipoprotein (VLDL) cholesterol were estimated according to the equation of Friedewald et al., ( $19 \mathrm{Vr})$.

\section{Determination of Hematological Profile:}

Heamoglobin $(\mathrm{Hb})$ and heamatocrit $(\mathrm{HcT})$ concentrations were determined according to Drabkin (19 99 ) and Inory (190s), respectively. Red blood cells (RBCs) and white blood cells (WBCs) count were estimated according to Dacie and Lewis, ( 991 ), respectively.

\section{Statistical Analysis:}

Autopsy samples were taken from the liver and kidney of rats in different groups and fixed in 1. $\%$ formalin solution. The results were expressed as mean \pm standard error (SE). The statistical analysis was carried out by using SPSS, PC statistical software (Verion $1 \wedge$. SPSS Inc., Chieago, USA) using the Dunk 'test multiple range post-hoc test. Data were analyzed by one way analysis variance (ANOVA). The values were considered significantly different at $\mathrm{P}<\cdot . \bullet$ (Snedecor and Cochran, 191.). 


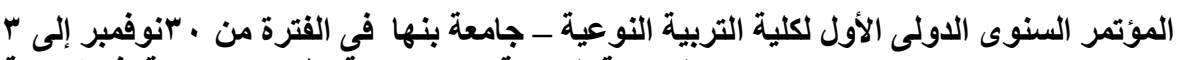

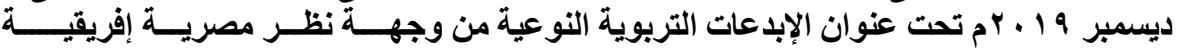

Results and Discussion

Chemical Composition of Red Grape and Kiwi Fruits as Raw Materials

Chemical composition of Kiwifruits was investigated on fresh weight basis. The following parameters were determined for moisture, protein, ash, carbohydrate, crude fiber, fat and the contents of vitamins (B ', B ${ }^{r}$, vitamin $C$, folate, vitamin A, total carotnoids and vitamin $E$ ) in addition some minerals including $(\mathrm{Ca}, \mathrm{Na}, \mathrm{K}, \mathrm{Fe}, \mathrm{Mg}, \mathrm{Zn}$,) and total antioxidant activity by DPPH\%. On the other side, results in Table $(r)$ indicated that Kiwifruit had the highest contents of these vitamins and minerals including vitamin $\mathrm{C}$, total carotnoids, Vitamin E, Vitamin A, Ca, Na, and total antioxidant .On the other hand, these results are the same line with those reported by Singletary, $(r \cdot 1 r)$ and Donno et al., $(r+1 r)$ they demonstrated that Kiwi are excellent sources of the ascorbic acid. According to Cangi, et al., $(r \cdot \mid l)$ indicated that Kiwifruit is one of the major dietary sources of various antioxidant for humans, and it's particularly also contains a wide range of other phytochemicals. In addition, Solanki and Bhatt, $(r+1$.$) showed that the natural antioxidants such as vitamin-$ $\mathrm{C}, \beta$-carotene and vitamin $\mathrm{E}$ prevent lipid peroxidation in the body. In fact from our results showed that red grape and Kiwifruits have major source of various types of nutrients with promising evidence of health benefits.

Chemical composition of red grape showed in table 1 and $r$ according to Salem A. and Saltana, $(r \cdot 10)$ whose demonstrated that red grape have a high content of calcium, magnesium, phosphor, potassium, iron, vitamin $\mathrm{A}$, vitamin $\mathrm{C}$ and total phenolic content. 


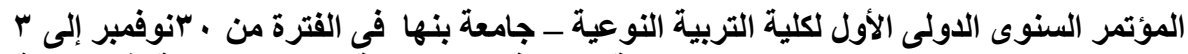

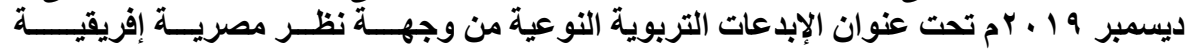

Table (1): Chemical Composition of Red Grape and Kiwi Fruits $(\mathrm{g} / \mathrm{l} \cdot \mathrm{g}$ edible portion).

\begin{tabular}{|c|c|c|}
\hline Chemical composition & Red Grape & Kiwi \\
\hline Moisture & VT.T. & $\lambda \cdot . \lambda 1$ \\
\hline Protein & r.r. & .1 .19 \\
\hline Carbohydrate & rч.६. & .9 .01 \\
\hline Fat & 0.1. & $\cdots .71$ \\
\hline Ash & $\cdot . \varepsilon r$ & . \\
\hline Curde fiber & $11 . r$. & $\cdot\{. \wedge 1$ \\
\hline
\end{tabular}

Table ( $r$ ): Vitamins and Minerals Content of Red Grape and Kiwi Fruit (mg/1..g edible portion).

\begin{tabular}{|c|c|c|}
\hline Vitamins and minerals & Red Grape & Kiwi \\
\hline Vitamin C & $1 \cdot .7 \pi$ & 90.00 \\
\hline Vitamin B I &. .79 & $\because .0$ \\
\hline Vitamin B ${ }^{Y}$ & $\because \cdot V$ & $\cdots \cdot r$ \\
\hline Vitamin E &. .19 & 1.00 \\
\hline Folate $(\mu \mathrm{g})$ & $\because \cdots r$ & - \\
\hline Total carotenoids & 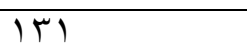 & E.rT \\
\hline Vitamin A ( $\mu \mathrm{g})$ & Ar & $1 \cdot \varepsilon \ldots$ \\
\hline $\mathbf{C a}$ & 17 & $r \cdot .7$ \\
\hline NA & $\because \leqslant \leqslant$ & $. r . \cdot 1$ \\
\hline $\mathbf{K}$ & 190 & TIY.O. \\
\hline $\mathbf{F e}$ &.. $\mathrm{VT}$ & $\cdots r \mu$ \\
\hline $\mathbf{Z n}$ & .911 & $\cdots .1 \varepsilon$ \\
\hline $\mathrm{Mg}$ & $\hat{\Lambda}_{.} \cdot$ & $T V^{\prime} \cdot T^{\prime}$ \\
\hline $\begin{array}{l}\text { Total antioxidant activity by DPPH\% } \\
(\mu \mathrm{g} / \mathrm{ml})\end{array}$ & 11.70 & 7.17 \\
\hline
\end{tabular}




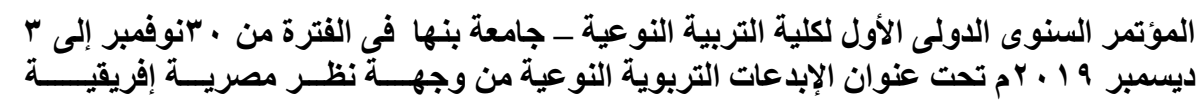

Effect of Administration of Red Grape Juice and Kiwi Juice at Different Levels on Nutritional Parameters of Rats

The mean value of feed intake (g/day for each rat) and body weight gain $\%$ of rats fed negative control group, positive control group were investigated and summarized in Table $(\Psi)$. Results revealed that the positive control group caused significant increase $(\mathrm{P}<\cdot . \cdot 0)$ in the mean value of feed intake compared to the negative control group $(r \cdot, 0 \cdot \pm \cdot, r)$ and $\quad I \leqslant . r r_{ \pm} \cdot r V$ respectively). Oral administration of grape juice ( $\odot \mathrm{ml}$ from $\wedge . \%$ water red grape) caused significantly decreased feed intake compared to the positive control group ( $Y \wedge . \Upsilon^{\prime} \pm \cdot . \leqslant q$ , and $r_{0} \cdot 0 \cdot \pm \cdot r$, respectively ) also body weight gain decreased significantly in group $r$ when compared with positive control group. When rats administrated $1 \cdot \mathrm{ml}$ of red grape juice the feed intake and body weight gain decreased significantly compared to positive control group. In the same line when rats administrated ${ }^{\circ} \mathrm{ml}$ and $1 \cdot \mathrm{ml}$ of kiwi juice feed intake and body weight gain decreased significantly compared to the positive control group.

Tabulated results indicated that when rats administrated of red grape juice in groups $r$ and $\varepsilon$ feed intake and body weight gain decreased significantly when compared with positive control group because red grape low in calories and virtually fat free so, red grape may help accelerate the pace of body weight loss programme. Red grape have a natural source of resveratrol, a powerful antioxidant that might also have some weight loss benefits, and they also offer a small amount of satiating fibre. Eating red grapes may give a great weight loss results too. This is because ellagic acid found only in red grapes is known to have positive fat-burning effects. Ellagic acid helps in slowing down the growth of existing fat cells in our body and deters the formation of new fat cells. 


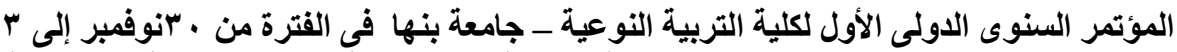

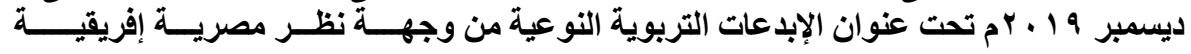

The feed intake and body weight gain in groups 0 and 7 decreased significantly as compared to control positive group, this data

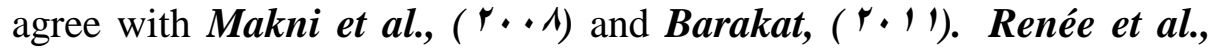
$(r \cdot 11)$ indicted that when $\&$ people with prediabetes eats two kiwis per day for I $r$ week which higher vitamin $\mathrm{C}$ levels, a reduction in blood pressure, and a $1 . r$-inch $(r .1 \mathrm{~cm})$ reduction in waist circumference.

Table ( $($ ): Effect of Administration of Red Grape Juice and Kiwi Juice at Different Levels on Nutritional Parameters of Rats

\begin{tabular}{|c|c|c|}
\hline $\begin{array}{l}\text { Parameters } \\
\text { Groups }\end{array}$ & FI (g/day) & BWG (g) \\
\hline$G^{\prime}($ Control -ve) & $1 \varepsilon . r r_{ \pm} \cdot r V^{d}$ & $1 \Gamma .77 \pm \cdot . \wedge 1$ \\
\hline Gr $^{r}$ (Control +ve $r \cdot \%$ Potato) & $\mu_{0} 0 \cdot \pm \cdot . \mu^{a}$ & $\varepsilon r .7 \neg \pm \nearrow . \Sigma \wedge$ \\
\hline $\begin{array}{l}\text { G }^{r} \text { (Potato } r \cdot \%++^{\ominus} \text { ml Grape } \\
\text { Juice) }\end{array}$ & $r r_{ \pm} \cdot . \leqslant q^{b} . Y \wedge$ & $11 . \cdots \pm r .7 \varepsilon$ \\
\hline $\begin{array}{l}\text { G\& } \quad \text { (Potato }{ }^{r} \% \\
\text { Grape Juice) }\end{array}$ & $r .7 \cdot \pm \cdot .9 r^{\mathrm{ab}}$ & $r \cdot .77_{ \pm} \varepsilon .77$ \\
\hline $\begin{array}{l}\text { G }^{\bullet}\left(\text { Potato }^{r} \cdot \%++^{\bullet} \mathrm{ml} \text { Kiwi }\right. \\
\text { Juice) }\end{array}$ & $r \neg.\urcorner \wedge_{ \pm} \cdot . \varepsilon q b c$ & $19 . r \mu \pm r . \wedge \varepsilon$ \\
\hline $\begin{array}{l}\text { Gq (Potato } r \cdot \%+l \cdot \text { ml Kiwi } \\
\text { Juice) }\end{array}$ & $Y \leqslant . V \cdot \pm \cdot .19^{c}$ & Yr. $\neg \pm 1 . Y$. \\
\hline
\end{tabular}

Values are expressed as means \pm SE.

Values at the same column with different letters are significantly different at $\mathrm{P}<\cdot . \cdot 0$.

\section{Effect of Administration of Red Grape Juice and Kiwi Juice at Different Levels on Liver Functions of Rats}

The activities of serum ALT and AST enzymes in all groups are presented in table $(\varepsilon)$. The mean values of ALT and AST activities were 
increased in positive control rats which were $r, r_{ \pm} r_{ \pm}, \wedge 0$ and $\varepsilon \cdot . \cdot \pm r . \wedge$ $\mathrm{U} / \mathrm{L}$, respectively, compared to negative control group with the mean values of $19 . r_{ \pm}+r . \vee r$ and $r 1 . r r_{ \pm} r . r \wedge \mathrm{U} / \mathrm{L}$, respectively. The levels of above enzymes activity were reduced in all treated groups when compared with positive control group.

The results in the same line with Mukherjee et al., $(r .1 r)$ and Jimenez et al., ( $r$. . s) whose demonstrated that intake of red grape decreased the serum levels of alanine aminotransferase (ALT) and aspartate aminotransferase (AST), blood markers of liver damage. Additionally, enhanced levels of ALT and AST in group of red grape supplemented. Moreover, treatment with ${ }^{\circ} \mathrm{mg} / \mathrm{kg}$ red grape alone was unlikely to produce a significant alteration in the rat liver weight as well as the activity of transaminase enzymes.

A common antioxidant called pyrroloquinoline quinone, or PQQ that is found in soil and many foods, including kiwi, was found to protect mice against the liver disease. When given to obese mouse mothers during pregnancy and lactation, PQQ protected their offspring from developing symptoms of liver fat and also prevented damage that could lead to developing the liver disease.

Table ( ): Effect of Administration of Red Grape Juice and Kiwi Juice at Different Levels on Liver Functions of Rats

\begin{tabular}{|c|c|c|}
\hline $\begin{array}{r}\text { Parameters } \\
\text { Groups }\end{array}$ & ALT(U/L) & $\mathbf{A S T}(\mathbf{U} / \mathbf{L})$ \\
\hline$G^{\prime}($ Control -ve $)$ & $19.77 \pm Y . V Y^{\mathrm{ab}}$ & $r ! . r \mu \pm r . r \Lambda^{b}$ \\
\hline Gr (Control +ve $r \cdot \%$ Potato) $^{r}$ & $r) . r M \pm 1.10^{a}$ & $\varepsilon \cdot \cdot \pm r \cdot \cdot \wedge^{\mathrm{a}}$ \\
\hline $\mathbf{G}^{r}\left(\right.$ Potato $^{r} \cdot \%+^{\ominus} \mathrm{ml}$ Grape Juice $)$ & $\begin{array}{l}19.77 \\
\pm \cdot . \wedge \wedge^{a b}\end{array}$ & 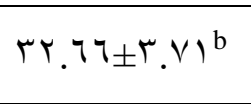 \\
\hline $\mathbf{G}^{\varepsilon}($ Potato $r \cdot \%+1 \cdot$ ml Grape Juice $)$ & $\| \vee . \mu_{ \pm} \cdot . \wedge \Lambda^{b}$ & $r V . r \mu_{ \pm} . \varepsilon 0^{a b}$ \\
\hline $\mathrm{G}^{\bullet}\left(\right.$ Potato $^{r} \cdot \%+^{\bullet} \mathbf{~ m l}$ Kiwi Juice $)$ & $1 \wedge . \cdots \pm r_{.} \cdot \wedge^{b}$ & $r q . \cdots \pm \varepsilon . r 0^{b}$ \\
\hline G` $^{`}$ Potato $r \cdot \%+1 \cdot$ ml Kiwi Juice) & $V \vee r Y_{ \pm} \cdot . \wedge \wedge^{b}$ & $r 1 . \cdots \pm 1.0 r^{b}$ \\
\hline
\end{tabular}




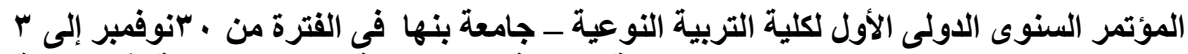

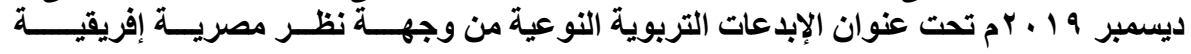

\section{Effect of Administration of Red Grape Juice and Kiwi Juice at Different Levels on Kidney Functions of Rats}

The effect of administration of red grape juice and kiwi juice at different levels on kidney functions such as creatinine and urea nitrogen is showed on table $\left({ }^{\circ}\right)$. Results showed significantly increased of serum creatinine and urea nitrogen in positive control group which were

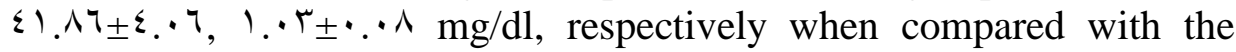
negative control rats which were $r \wedge .07 \pm r .+1 \vee$ and $\cdot .91 \pm \cdot .{ }^{9} \mathrm{mg} / \mathrm{dl}$, respectively. When rats administrated orally red grape juice and kiwi juice $\left({ }^{\circ} \mathrm{ml}\right.$ and $\left.1 \cdot \mathrm{ml}\right)$ serum urea nitrogen and creatinine decreased significantly $\left(P<\because{ }^{\circ}\right)$ when compared with the positive control group as shown in table $\left({ }^{\circ}\right)$.

Red grape improves some kidney function parameters as it enhances GFR and clearly lowers proteinuria. Zeeuw et al., $(r \ldots$ s) demonstrated that red grape importance as reduction in proteinuria to the lowest achievable level is an important predictor of long term renal protection, as it is increasingly recognized that proteinuria may actually be pathological and etiological in CKD progress and not just symptomatic. Red grape effect on plasma, urine urea and uric acid, its clinical use could be envisaged as a uric acid-lowering therapy substitute to allopurinol. High potassium intakes of kiwi are also associated with a reduced risk of stroke, protection against loss of muscle mass, preservation of bone mineral density, and reduction in the formation of kidney stones. 


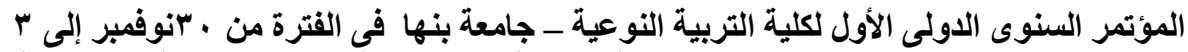

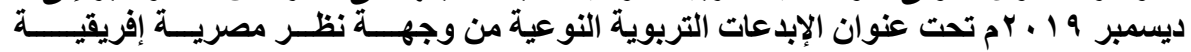

Table ( $\bullet$ ): Effect of Administration of Red Grape Juice and Kiwi Juice at Different Levels on Kidney Functions of Rats

\begin{tabular}{|c|c|c|}
\hline Parameters & $\begin{array}{ll}\text { Urea } & \text { Nitrogen } \\
(m g / d l) & \end{array}$ & $\begin{array}{l}\text { Creatinine } \\
(m g / d l)\end{array}$ \\
\hline$G^{\prime}($ Control -ve) & $r{ }^{0} .07 \pm r^{\prime} \cdot l^{\mathrm{ab}}$ & $.91 \pm \cdot .99 \mathrm{ab}$ \\
\hline Gr $^{r}$ (Control +ve $r \cdot \%$ Potato) & $\varepsilon) . \wedge \neg \pm \varepsilon . \cdot 7^{\mathrm{a}}$ & $1 . \cdot r \pm \cdot . \cdot \lambda^{\mathrm{a}}$ \\
\hline $\begin{array}{l}\text { Gr }^{r} \text { (Potato } r \cdot \%++^{\ominus} \text { ml Grape } \\
\text { Juice) }\end{array}$ & $\Gamma \varepsilon . \neg \cdot \pm 1 . \wedge \cdot b$ & $\cdot . \wedge \cdot \pm \cdot .0^{\mathrm{b}}$ \\
\hline $\begin{array}{l}\mathrm{G}^{\varepsilon} \quad \text { (Potato }^{Y} \cdot \% \\
\text { Grape Juice) }\end{array}$ & $r \varepsilon . r \pm \cdot r \varepsilon^{b}$ & $\because V_{ \pm} \cdot . \mu_{q b}$ \\
\hline $\begin{array}{l}\text { G }^{\bullet} \text { (Potato } r \cdot \%++^{\ominus} \text { ml Kiwi } \\
\text { Juice) }\end{array}$ & $r \varepsilon . r \cdot \pm \cdot . q r^{b}$ & $\cdot V \Delta_{ \pm} \cdot . r \wedge^{b}$ \\
\hline $\begin{array}{l}\text { G }{ }^{\uparrow}\left(\text { Potato }^{r} \cdot \%+1 \cdot \text { ml Kiwi }\right. \\
\text { Juice) }\end{array}$ & $\Gamma^{\top} . \wedge \neg \pm \cdot . \vee \wedge^{c}$ & $\because Y Y_{ \pm} \cdot .1 \leq \varepsilon^{b}$ \\
\hline
\end{tabular}

\section{Effect of Administration of Red Grape Juice and Kiwi Juice at Different Levels on on Lipid Profile in Rats}

Data in table ( 7 ) showed that addition of potato chips on basel diet in normal rats caused significant $(P<\cdot .0)$ increased lipid profile in serum such as TC, TG, LDL-C and VLDL-C in positive control group compared with negative control group however, there were significant decrease in serum HDL-c in positive control group when compared to other all groups. On the other hand, the oral administration of red grape juice and kiwi juice at different levels $\left({ }^{\circ} \mathrm{ml}\right.$ and $\left.1 \cdot \mathrm{ml}\right)$ had decreased in serum levels of TC, TG, VLDL-c, and LDL-c as compared to the positive control group, While had a significant increase $(\mathrm{p}<\cdot . \cdot 0)$ in serum level of serum HDL-c, compared to the positive control group. The greatest decrease of lipid profile was noted for group ( 7 ) when rats fed on diet supplemented with $r . \%$ potato chips and given orally $1 \cdot$ ml kiwi juice daily for ${ }^{7}$ weeks. 


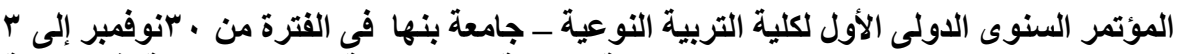

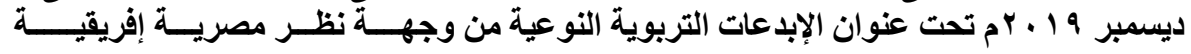

Red grape and kiwi and fruits contained the antioxidant including flavonoid compounds and vitamins which inhibit oxidation of low density lipoprotein (LDL-C), a critical event in the pathogenesis of atherosclerosis through alternative mechanisms, including improvement of endothelial function, inhibition of platelet agreeability and a decrease in the risk of plaque rupture (Fayed et al., $r \cdot 1 \cdot$ ).

Hansen et al., ( $r . .0)$ indicated that red grape consumption is associated with beneficial changes in blood lipids and fibrinogen that may help to reduce the cardiovascular risk factors. The polyphenols of red grape have virtually no effect on the investigated traditional risk factors for CVD.

This results at the same line with Brevik et al., $(r \cdot 1$ ') whose noted that Kiwifruit intervention improved blood antioxidant status and lowered markers of lipid peroxidation. Diet supplemented with Kiwifruits per day decreased fasting plasma TG levels but did not affect plasma levels of total cholesterol, HDL, LDL or glucose. Moreover, Rodriguez et al., $(r .1 \%)$ showed that some trace elements of kiwi contribute to the function of endogenous antioxidant enzymes by acting as cofactors, and most polyphenols can act as chain breakers or radical scavengers and prevent the oxidation of low density lipoproteins (LDL). Also, kiwi rich in vitamin $C$ which reduces the tocopheroxyl radical formed by interaction of $\alpha$-tocopherol with lipid peroxides in cell membranes, this demonstrates the wide variety of reactive intermediates vitamin $\mathrm{C}$ interacts to maintain the function of cellular components. In addition kiwi have Lutein which a carotene that prevents the eyes from developing cataracts. Beta sitosterol can inhibit the absorption of cholesterol by the intestine leading to a lower concentration of cholesterol in blood published by (Moreno et al., r.. v; Naveh et al., r. I r and Fulgoni et al., r. 1 r).

These results are supported by the findings of Chang et al., $(r \cdot 1 \cdot)$ they indicated that consumption of two Kiwifruit per day for $\wedge$ weeks by hypercholesterolemic subjects appeared to reduce some indices 


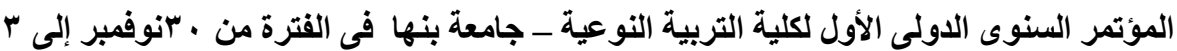

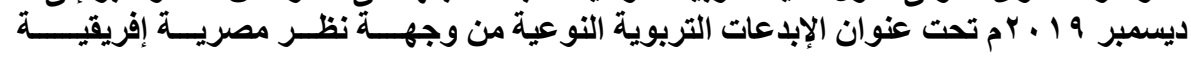

of blood lipid profiles and was associated with diminished LDL, VLDL, and TC.

Table ( 7$)$ : Effect of Administration of Red Grape Juice and Kiwi Juice at Different Levels on Lipid Profile in Rats 


\begin{tabular}{|c|c|c|c|c|c|}
\hline $\begin{array}{l}\text { Parameters } \\
\text { Groups }\end{array}$ & $\begin{array}{l}\text { TC } \\
(\mathrm{mg} / \mathrm{dl})\end{array}$ & $\begin{array}{l}\text { TG } \\
(\mathrm{mg} / \mathrm{dl})\end{array}$ & $\begin{array}{l}\text { HDL-C } \\
\text { (mg/dl) }\end{array}$ & $\begin{array}{l}\text { LDL-C } \\
\text { (mg/dl) }\end{array}$ & $\begin{array}{l}\text { VLDL-C } \\
(\mathrm{mg} / \mathrm{dl})\end{array}$ \\
\hline$G^{\prime}($ Control -ve) & $V Y . \leqslant T \pm Y .0 \varepsilon^{b c}$ & $19 . \cdot \pm 0.19^{d}$ & $\Sigma \vee . \neg 7 \pm \cdot . \wedge v^{b c}$ & $r q . \cdot r \pm 1 . \wedge \varepsilon^{d}$ & $\mid V . \wedge \cdot \pm 1 . M^{b}$ \\
\hline $\begin{array}{l}\text { G } \quad \text { (Control +ve } \\
r \cdot \% \text { Potato) }\end{array}$ & $\begin{array}{l}119 . \varepsilon \cdot \pm \Lambda . \varepsilon 1 \\
\mathrm{a}\end{array}$ & $1 \wedge 1.7 r \pm r \wedge . r 0^{a}$ & $\varepsilon 1 . \cdots \pm r . r q^{c}$ & $V \tau .17 \pm \tau . \cdot v^{\mathrm{a}}$ & $r Y . V \cdot \pm 0.70^{a}$ \\
\hline $\begin{array}{l}\mathbf{G}^{\Gamma} \quad \text { (Potato }^{r} \% \\
\text { ml Grape Juice) }\end{array}$ & $\wedge \varepsilon .7 \cdot \pm 7.99 \mathrm{~b}$ & $\left|r \varepsilon . \cdot r_{ \pm}\right| r_{.} \mid \cdot b$ & $07 . r_{ \pm} 0 . r^{\mathrm{ab}}$ & ${ }_{c}^{o r} \cdot \wedge r \pm r .0 \cdot b$ & $r r \cdot r \cdot \pm r \cdot \nu^{a}$ \\
\hline $\begin{array}{l}\text { G }\{\text { (Potato } r \%+1 \cdot \\
\text { ml Grape Juice) }\end{array}$ & $V r .17 \pm 1.0 r^{b c}$ & $1.0 . r 7 \pm 9 . r \varepsilon^{c}$ & $0 \leqslant .1 r \pm T .1 \leqslant \mathrm{~b}$ & $\varepsilon \Lambda .1 \tau_{ \pm} \cdot . \vee \mu^{b c}$ & $r 1.0_{ \pm} \cdot \cdot 1^{a}$ \\
\hline $\begin{array}{l}\text { G }^{\bullet} \text { (Potato }^{r} \% \quad+\bullet \\
\text { ml Kiwi Juice) }\end{array}$ & $\vee \circ \cdot \wedge \tau_{ \pm} \wedge . \cdot \wedge^{b c}$ & $1 \cdot r \cdot \cdots \pm r \cdot r^{c}$ & $71.9 \cdot \pm 7.10^{a}$ & $0 \wedge . \vee \neg \pm r . \wedge r^{b}$ & $r) \cdot r_{ \pm} \cdot \varepsilon \cdot 0^{a}$ \\
\hline 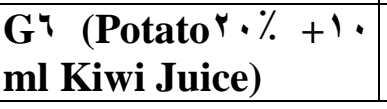 & $07 . r 7 \pm r . r \varepsilon^{c}$ & $1 . \varepsilon . r \neg \pm V . .0^{c}$ & $01.17 \pm \varepsilon .10^{b}$ & $\left.r^{\prime}\right) r_{ \pm 1} . \vee q^{d}$ & $r \cdot . \vee \wedge \pm l . \Sigma)^{a b}$ \\
\hline
\end{tabular}

$1 \leq 1$ 


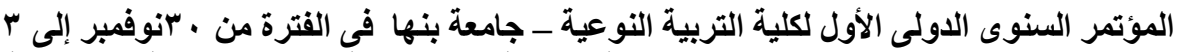

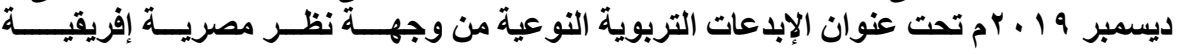

Effect of Administration of Red Grape Juice and Kiwi Juice at Different Levels on Serum Concentrations of Antioxidant Activity and Malondialdehyide on Rats

The effect of administration of red grape juice and kiwi juice at different levels on serum concentrations of antioxidant activity such as CAT and SOD in addition Malondialdehyide presented in table ( $\vee$ ). Results showed that there were significantly decreased of serum CAT and SOD in positive control group when compared with the negative control group. However, serum CAT and SOD increased significantly $\left(P<\cdot .{ }^{\circ}\right)$ in groups $r, \Sigma, 0$ and $r$ significantly when compared with the positive control group. Moreover, the best value of CAT was noted in group 7 but the great value of SOD was noted in group $r$. On the other hand, results showed that there were increased of malondialdehyide significantly in positive control group when compared to the negative control group. Serum MDA in groups $r, \Sigma, 0$ and $\uparrow$ groups were decreased significantly $(P$ $<\cdot .0$ ) when compared with the positive control group.

Red grape and Kiwifruits have a fairly high phenolic content in comparison to some other fruits (Venter, r.1\%). Fruit and vegetables generally have a high phenolic content, with the composition varying between different kinds (Imeh and Khokhar, r.. r). Phenolic compounds are secondary metabolites abundant in fruit and vegetables and have various functional attributes). The interest in phenolic compounds has increased over recent years due to their potential health benefits, protective function (Kim and Lee, r... o).

Total antioxidant capacity of red grape and Kiwifruit reported greater than grapefruit, apple, and pear (Beekwilder et al., r... Q). In vitro antioxidant assays of several fruit juices including those prepared from red grape and kiwifruit juice was determined to be a rich source of potentially antioxidant polyphenols (Iwasawa et al., r. 'l). Furthermore, Kiwifruit juice was observed to be a potent inhibitor of lipid oxidation and an effective eliminator of the oxidative stress inducing agent hydrogen peroxide $\left(\mathrm{H}^{\Upsilon} \mathrm{O} r\right)$ showed by Venter, $(r \cdot 1 \%)$. 


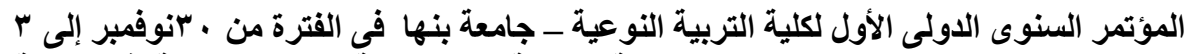

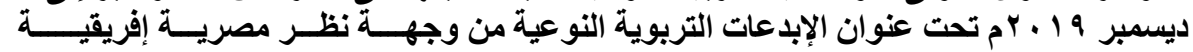

In addition, higher concentration of resveratrol, a component of grape juice, acting on free radicals and defending the organism against possible inflammation (Shivraj et al., $\left.\boldsymbol{r}^{\prime} \boldsymbol{r}\right)$. SOD is a mitochondrial antioxidant enzyme encoded in the nucleus, it is essential for the removal of superoxide radicals. CAT immunoexpression increased in the group treated with grape juice $1 \%$. Costa et al., $(r, 1)$ indicated that CAT is an important enzyme in response of oxidative stress by catalyzing the hydrolysis reaction of hydrogen peroxide molecules in water and oxygen. In this way, it can be suggest a possible protective role of grape juice treatment.

Table ( $\vee$ ): Effect of Administration of Red Grape Juice and Kiwi Juice at Different Levels on Serum Concentrations of Antioxidant Activity and Malondialdehyide on Rats.

\begin{tabular}{|c|c|c|c|}
\hline $\begin{array}{ll}\text { Parameters } & \\
\text { Groups }\end{array}$ & $\begin{array}{l}\text { CAT } \\
(\mathrm{U} / \mathrm{ml})\end{array}$ & $\begin{array}{l}\text { SOD } \\
(\mathrm{m} \mathrm{mol} / \mathrm{ml})\end{array}$ & $\begin{array}{l}\text { MDA } \\
(\mathbf{u} / \mathbf{m l})\end{array}$ \\
\hline$G^{\prime}($ Control -ve) & $\cdot .9 V_{ \pm} \cdot . \cdot r^{b}$ & $119.11 \pm r 0.11^{c}$ & $\cdot . \wedge r_{ \pm} \cdot .10^{b}$ \\
\hline $\begin{array}{l}\text { G (Control +ve r.\% } \\
\text { Potato) }\end{array}$ & $\cdot . q_{ \pm} \cdot . \cdot r^{c}$ & $119.0 \leqslant \pm \leqslant r .1 v^{d}$ & $1.1 \leqslant \pm \cdot . \cdot 0^{a}$ \\
\hline $\begin{array}{l}\mathbf{G}^{r} \quad \text { (Potato } r \cdot \% \quad+{ }^{\ominus} \quad \mathrm{ml} \\
\text { Grape Juice) }\end{array}$ & ${ }_{b}^{1} \cdot \cdot V_{ \pm} \cdot . \cdot T r$ & $r \neg \cdot r \cdot \pm 17 . \vee \wedge^{a}$ & $\cdot .70 \pm \cdot r \cdot$ \\
\hline $\begin{array}{l}\text { G } \leqslant \text { (Potato }{ }^{r} \%+1 \cdot \mathrm{ml} \\
\text { Grape Juice) }\end{array}$ & ${ }_{b}^{1} \cdot V_{ \pm} \cdot . \cdot \varepsilon r$ & $r \cdot \wedge_{.} .0 \Lambda_{ \pm} \varepsilon r . r \neg b c$ & $\cdot 97 \pm \cdot . \cdot r^{a b}$ \\
\hline $\begin{array}{l}\mathrm{G}^{\bullet} \text { (Potato } r \cdot \% \text { + } \text { (Pl }^{\circ} \mathrm{ml} \\
\text { Kiwi Juice) }\end{array}$ & $1 . r r_{ \pm} \cdot .1 \varepsilon^{a}$ & $r) 9.1 \leqslant \pm r . V V^{b}$ & $\left..9 r_{ \pm} \cdot . \varepsilon \leqslant\right)^{\mathrm{ab}}$ \\
\hline $\begin{array}{l}\text { G' (Potato } r \cdot \%+l \cdot \mathbf{m l} \\
\text { Kiwi Juice) }\end{array}$ & $1 . r \tau_{ \pm} \cdot . \cdot \wedge^{\mathrm{a}}$ & $r \cdot \varepsilon . r r \pm \Psi . \cdot q b c$ & $\cdot V r_{ \pm} \cdot . r^{c}$ \\
\hline
\end{tabular}

\section{Effect of Administration of Red Grape juice and Kiwi} Juice at Different Levels on Hematological Profile on Rats.

A result of red grape juice and kiwi juice at different levels on hematological profile such as Hemoglobin, RBC, WBC, PCV lymph, meuto, mono and corin concentrations of rats are noted in Table ( 9 ). Re- 
sults revealed that positive control group had significant decrease $(\mathrm{P}<\cdot . \bullet)$ in all hematological profile when compared with other groups. However, when rats administrated orally of red grape juice and kiwi juice at different levels $\left({ }^{\circ} \mathrm{ml}\right.$ and $\left.1 \cdot \mathrm{ml}\right)$ all hematological profile had improved than positive control group. The greatest increase in the relative red blood cell parameters concentrations was obtained in group $r$.

The results in the same line with Nora , r. 11 who demonstrated that red grape improved iron status, serum iron, transferrin/total ironbinding capacity (TIBC), transferrin saturation, and ferritin are widely used in clinical practice,

Consumption of Gold kiwifruit has also been shown to improve Fe absorption in women with low-Fe status, probably due to the ability of vitamin $\mathrm{C}$ to enhance the absorption of non-haem Fe (Beck et al., r. l'). Kiwifruit are also a good source of vitamins $\mathrm{K}$ and $\mathrm{E}$, folate, fibre, polyphenols and carotenoids, and these compounds may also confer health benefits. Kiwifruit have been shown to improve digestive health, modulate lipid profiles and reduce platelet aggregation (Rush et al., r.. r). Kiwifruits have anticoagulation properties, diminish liver enzyme activity, and influence the RBC system in blood. Kiwifruits 'Hayward', regardless of the crop and postharvest ripening, affect pro-health properties and can be recommended particularly in patients with hyperlipidemia and hypercholesterolemia (Maria et al., r. $1 \%$ ).

In conclusion, red grape and kiwifruits have higher amounts of bioactive compounds and antioxidant capacity than other fruits. The high amounts of polyphenols, flavonoids, and vitamin $\mathrm{C}$, as well as a high antioxidant capacity, influenced the values of total cholesterol in the plasma of rats from groups containing conventional. A significant improvement in lipid parameters such as TC, LDL-C, and TG in rats fed diets containing kiwifruit was observed. This study showed that the increase in consumption of vitamin $\mathrm{C}$ was associated with an increase in HDL-C and decrease in total cholesterol and triglycerides. 


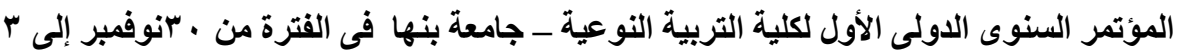

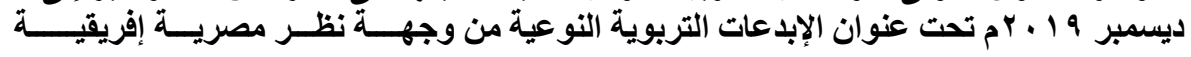

Table $(\wedge)$ : Effect of Administration of Red Grape juice and Kiwi Juice at Different Levels on Hematological Profile on Rats. 


\begin{tabular}{|c|c|c|c|c|c|c|c|c|}
\hline Proups & $\begin{array}{l}\text { Heam- } \\
\text { oglobin } \\
\text { (mg/dl) }\end{array}$ & $\begin{array}{l}\text { Red bold } \\
\text { cells } \\
(\mathrm{mg} / \mathrm{dl}) \\
\end{array}$ & $\begin{array}{c}\text { White blood } \\
\text { cells } \\
(\mathrm{mg} / \mathrm{dl})\end{array}$ & PCV & LYMPH & MEUTO & MONO & CORIN \\
\hline$G^{\prime}($ Control -ve) & $M, r \varepsilon_{ \pm} \cdot . r r^{a}$ & $0 . r_{ \pm} \cdot .1 v^{b}$ & 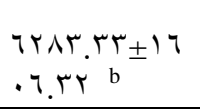 & $\sum \wedge^{\mathrm{a}} \cdot r r_{ \pm} \cdot . \wedge$ & $\varepsilon \cdot \because \cdots \pm \varepsilon$ & $0_{b}^{01} \cdot \cdots \pm r \cdot 0^{a}$ & $\begin{array}{l}\varepsilon . \tau_{ \pm} \\
77^{\mathrm{ab}}\end{array}$ & $r .7 T_{ \pm} \cdot r r$ \\
\hline $\begin{array}{l}\text { Gr }(\text { Control +ve } r \cdot \% \text { Pota- } \\
\text { to) }\end{array}$ & $1 \cdot .9 \varepsilon_{ \pm} 1 . \vee v^{b}$ & $0 . \cdots \pm \cdot .11^{b}$ & $\begin{array}{l}\vee \wedge q \cdot \ldots \\
\pm 0 r \cdot \ldots \cdot r^{a}\end{array}$ & $r^{\circ} \cdot \cdots \pm 1.0$ & $\begin{array}{l}\varepsilon q .7 \tau \pm r . \\
q . a\end{array}$ & $\varepsilon r . r r_{ \pm} . v T$ & 每 & $\mathrm{b} . \cdots \pm \cdot .0 \mathrm{~V}$ \\
\hline 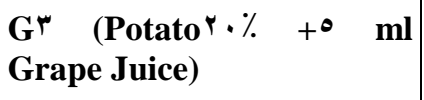 & $1 Y .17_{ \pm} \cdot . \wedge^{\mathrm{a}}$ & $\neg . \wedge 1 \pm 1 .(1)^{a}$ & $\begin{array}{l}70 \ldots \cdots \pm 11 \\
97^{\mathrm{ab}}\end{array}$ & $\gamma_{\gamma^{a b}} \mu^{\mathrm{ab}} \cdot \cdot \pm \cdot .0$ & $r_{0,}^{r} \cdot \cdots \pm r$ & or... $\ldots 1 .$. a & 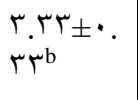 & $\mathrm{r}_{\mathrm{b}} \cdot \mathrm{r} \mathrm{r}_{ \pm} \cdot . \mathrm{T}$ \\
\hline $\begin{array}{l}\text { G }\left\{\text { (Potato }{ }^{r} \%+1 \cdot \quad \mathbf{m l}\right. \\
\text { Grape Juice) }\end{array}$ & $1 r_{.} \cdot r_{ \pm} \cdot .1 \leq \varepsilon^{a}$ & $\left\{.01 \pm \cdot .17^{b}\right.$ & 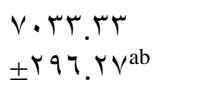 & $\begin{array}{l}r q \cdot r r_{ \pm 1} \cdot r \\
a b\end{array}$ & $\begin{array}{l}r r_{.} \tau^{\prime} \pm r \\
r . \mathrm{b}\end{array}$ & $0 \leq . \cdot \pm \cdot . v^{a}$ & $\begin{array}{l}0 . \cdots \pm \\
o v^{a}\end{array}$ & $\varepsilon . \cdots \pm \cdot .0 \mathrm{~V}$ \\
\hline $\begin{array}{l}\text { G }^{\bullet} \text { (Potato } r \cdot \%++^{\ominus} \text { ml Kiwi } \\
\text { Juice) }\end{array}$ & $11.9 \cdot \pm \cdot .1 \cdot a b$ & $\varepsilon \cdot v \cdot \pm \cdot . v^{b}$ & $\begin{array}{l}7977.7 \mathrm{~V} \\
\pm 770.90^{\mathrm{ab}}\end{array}$ & $\begin{array}{l}r \Lambda .7 \tau_{ \pm} \cdot{ }^{\prime} \wedge \\
\Lambda^{\mathrm{ab}}\end{array}$ & $\begin{array}{l}\text { \&1. } \cdots \pm 1 . \\
\text { orab }\end{array}$ & ${ }_{b}^{0 \cdot} \cdot 77 \pm r .11^{a}$ & 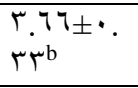 & מז. \\
\hline
\end{tabular}




\begin{tabular}{|c|c|c|c|c|c|c|c|c|}
\hline & & & & & & & & $\mathrm{b}$ \\
\hline $\begin{array}{l}\text { G }{ }^{\top} \text { (Potato }{ }^{r} \% \\
\text { Kiwi Juice) }\end{array}$ & $M r^{r} r_{ \pm} \cdot . \wedge^{a}$ & $0.0 r_{ \pm} \cdot .1 r^{b}$ & $\begin{array}{l}\text { EqVT. TV } \\
\pm T r \mid . V T^{c}\end{array}$ & $\varepsilon \cdot \cdot \cdots \pm \cdot \bullet$ & $\operatorname{or}_{\text {orb }} \cdot \cdots \pm 1$. & $01 \cdot \cdots \pm r \cdot \cdot 0 \mathrm{a}$ & 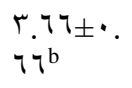 & ${ }_{\mathrm{a}}{ }_{\mathrm{a}} \mathrm{rr}_{ \pm} \cdot \mathrm{r}$ \\
\hline
\end{tabular}

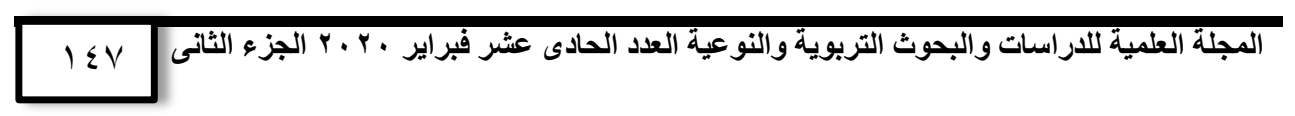




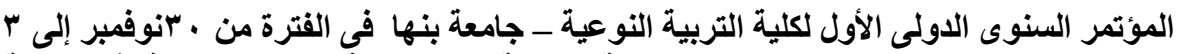

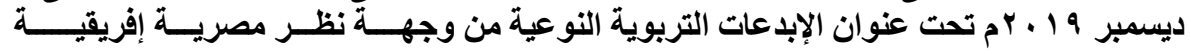

\section{Histopathological Examination of Liver:}

Microscopically, liver of rats from negative control group revealed the normal histological structure of hepatic lobule (Figs. 1). Some examined sections from positive control group showed slight vacuolation of hepatocytes and slight fibroplasia in the portal triad (Fig. $r$ ). Moreover, no histopathological changes were noticed in examined sections from groups $r, \varepsilon, 0$ and $T$

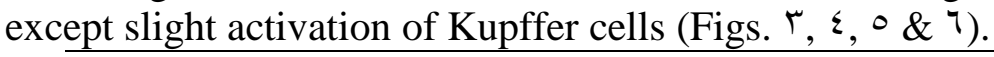

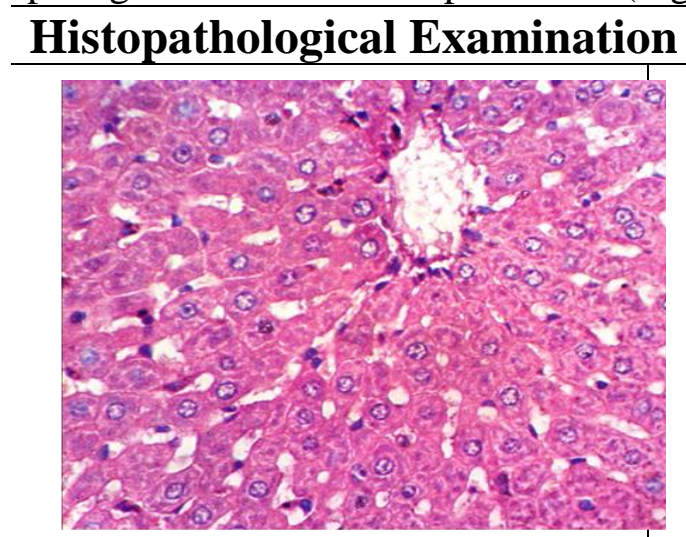

Fig. (1): Liver of rat from group 1 showing the normal histological structure of hepatic lobule $(\mathrm{H}$ $\left.\& \mathrm{E} X \_\cdots\right)$.

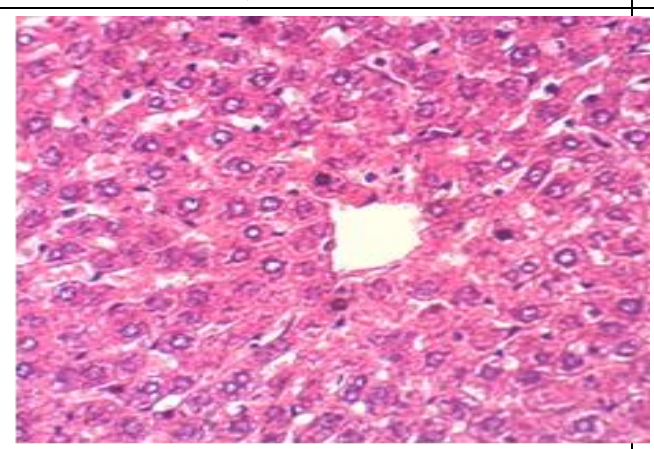

Fig. $(\stackrel{\sim}{)}$ : Liver of rat from group

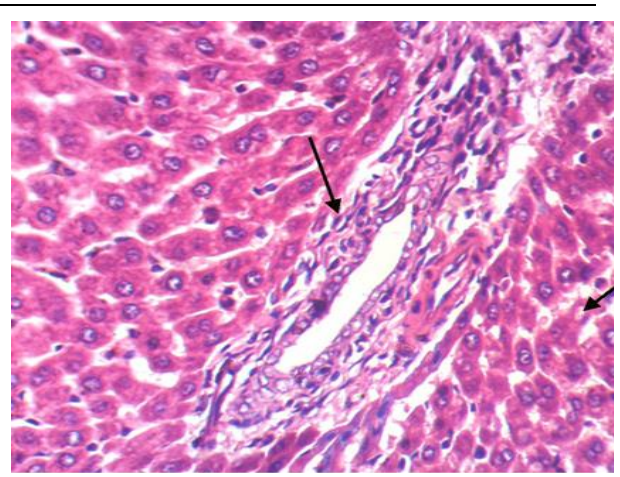

Fig. $(r)$ : Liver of rat from group $r$ showing slight vacuolation of hepatocytes and slight fibroplasia in the portal triad $(\mathrm{H} \& \mathrm{E} \mathrm{X} \leqslant \cdots)$.

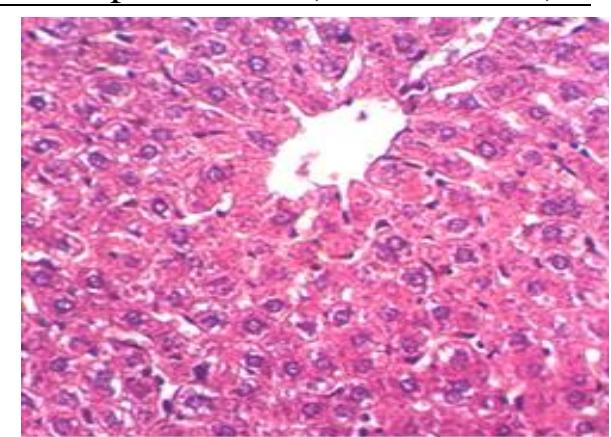

Fig. ( $)$ ): Liver of rat from group 


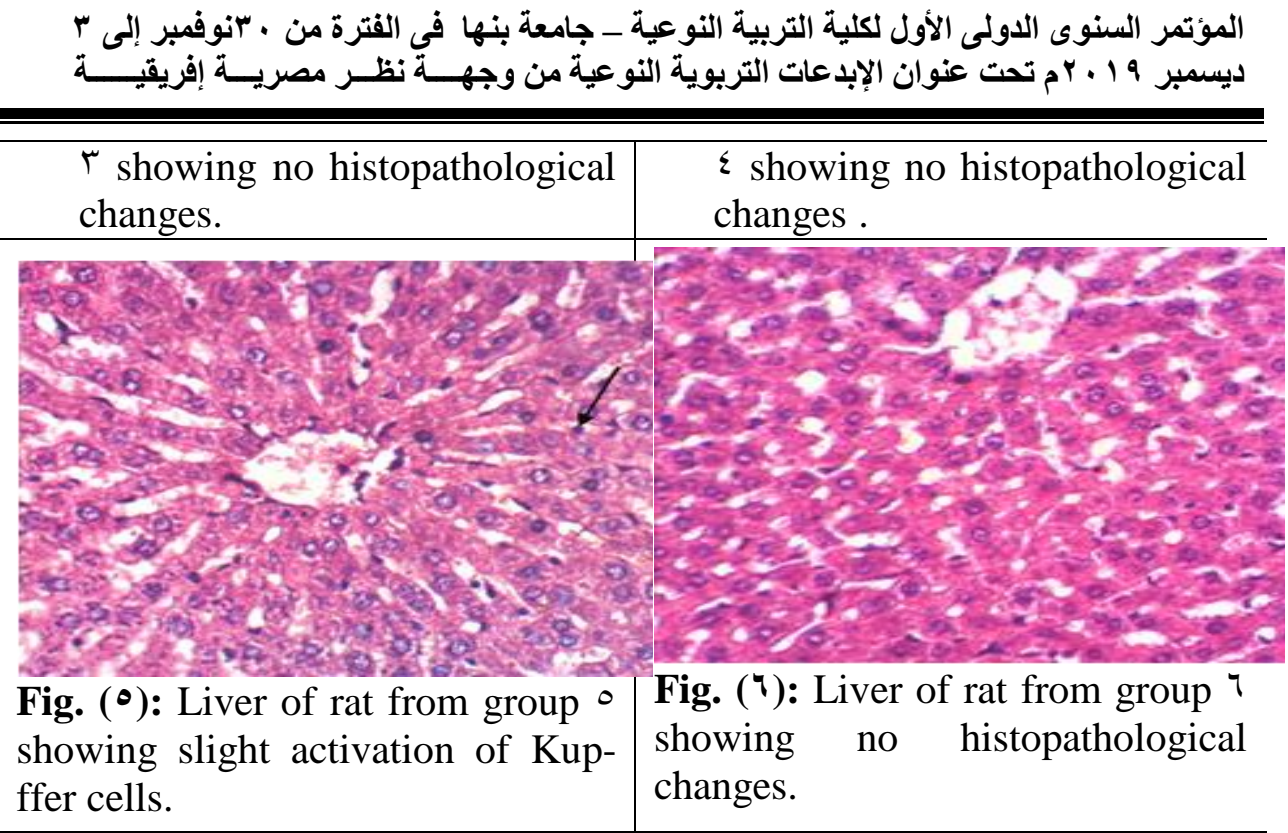

\section{Histopathological Examination of Kidneys:}

Microscopical examination of kidneys of rats from group 1 revealed the normal histological structure of renal tissue (Figs. $\vee$ ). However, some kidneys of rats from group $r$ revealed vacuolization of epithelial lining renal tubules (Fig. $\wedge$ ). Moreover, kidneys of rats from group $r$ showed no histopathological alterations (Fig. $\left.{ }^{9}\right)$. Examined sections from group $₹$ revealed no histopathological alterations (Figs. 1•). Meanwhile, kidneys of rats from groups 0 \& 7 showed no histopathological alterations except proteinaceous material in the lumen of some renal tubules (Figs. $11 \& \mid r$ ). 


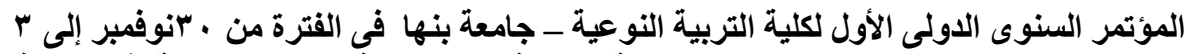

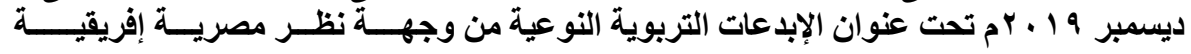

\section{Histopathological Examination of Kidneys}

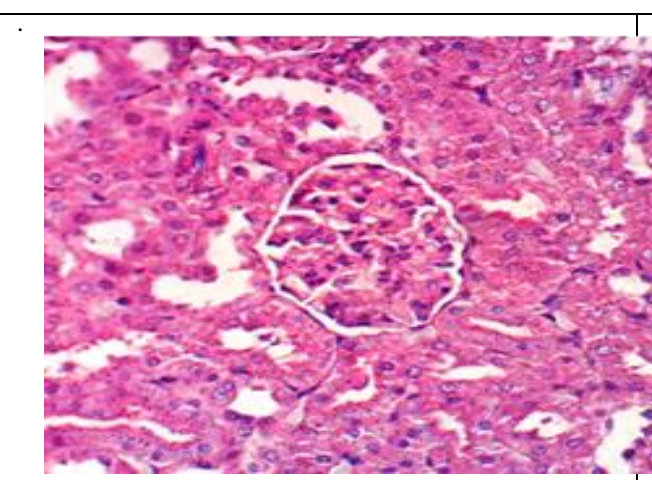

Fig. ( $\vee$ ): Kidney of rat from group 1 showing the normal histological structure of renal tissue

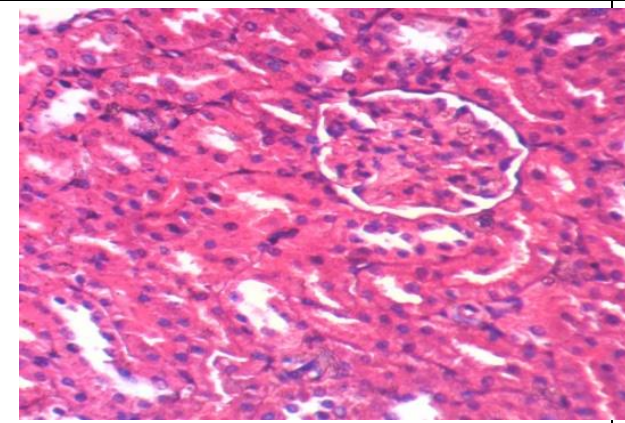

Fig. ( $\left.{ }^{9}\right)$ : Kidney of rat from group $r$ showing no histopathological alterations.

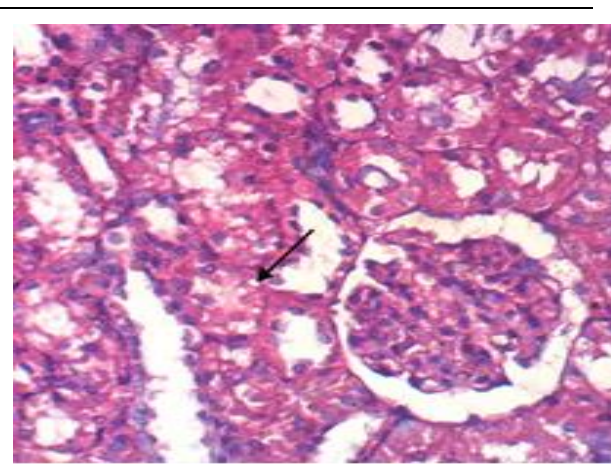

Fig. $(\wedge)$ : Kidney of rat from group $r$ showing vacuolization of epithelial lining renal tubules.

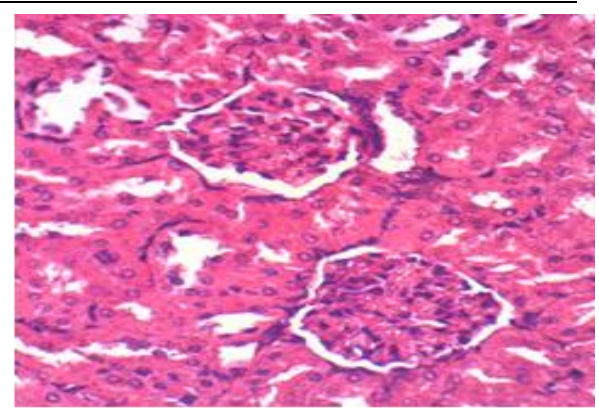

Fig. ( $1 \cdot)$ : Kidney of rat from group ₹ showing no histopathological alterations. 

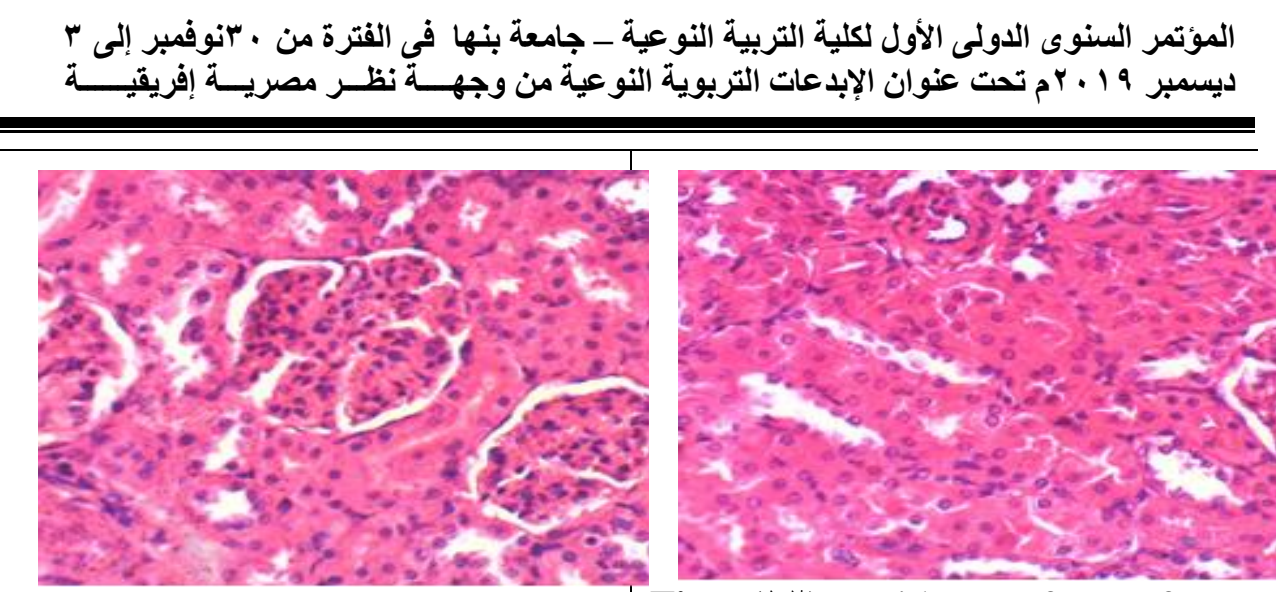

Fig. (11): Kidney of rat from group ${ }^{\circ}$ showing no histopathological alterations.

Fig. ( $Y$ Y): Kidney of rat from group ${ }^{\top} \mathrm{K}$ showing no histopathological alterations.

\section{References}

Aebi, H. ( $(9 \wedge \varepsilon)$ : Catalase in vitro. In: Methods of Enzymology; $1 \cdot 0$ : $|Y|-\mid Y T$.

Allain,C.; Poon,L. and Chan,C.( $(9 \vee \varepsilon)$ : Enzymatic determination on total serum cholesterol.Clin.chem; $r \cdot: \leqslant \vee \cdot-\varepsilon \vee 0$.

Barakat,L. $(r+11)$ : Hypolipidemic and Antiatherogenic Effects of Dietary Chitosan and Wheatbran in High Fat- High Cholesterol Fed Rats. Australian Journal of Basic and Applied Sciences; ${ }^{\circ}$ (1.): r. r r $r$.

Beck K., Conlon C., Kruger R. $(\uparrow \cdot 11)$ : Gold kiwifruit consumed with an iron-fortified breakfast cereal meal improves iron status in women with low iron stores: a 17 -week randomised controlled trial. Br J Nutr. 1.0, 1.1-1.9.

Beekwilder,J.; Hall,R. and DeVos,C. ( $\uparrow \ldots \bullet)$ : Identification and dietary relevance of antioxidants from raspberry. Bio. Factors $; Y r: 19 \vee Y Y \cdot 0$.

Brevik,A; Karlsen,A.; Azqueta,A.; Tirado,A.; Blomhoff,R. and Collins,A. $(r+11)$ : Both base excision repair and nucleotide 


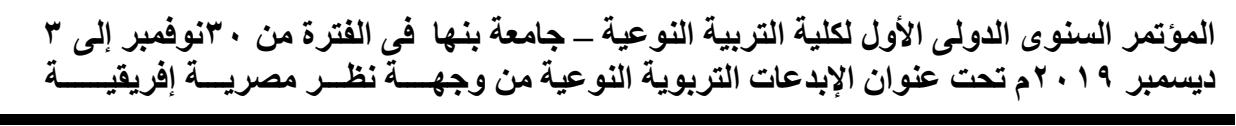

excision repair in humans are influenced by nutritional factors.

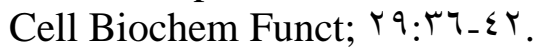

Cangi,R.; Altuntas,E.; Kaya,C. and Saracoglu,O. ( $\uparrow+11)$ : Some chemical and physical properties at physiological maturity and ripening period of Kiwifruit, African Journal of Biotechnology

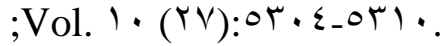

Ceriello A., Bortolotti N., Crescentini A., ( $(99 \wedge)$ : Antioxidant defenses are reduced during the oral glucose tolerance test in normal and non-insulin-dependent diabetic subjects. Eur J Clin Invest ; rA:rrq_rr.

Chang, C.; Lin, Y.; Lu Y.; Liu Y, and Liu J. (Y. $\cdot$ •): Kiwifruit improves bowel function in patients with irritable bowel syndrome with constipation. Asia Pac J Clin Nutr.; 19: $\{01$ _ $\leqslant 0 \mathrm{~V}$.

Costa L., Badawi A., amd El-Sohemy A. $(r+\mid r)$ : Nutrigenetics and modulation of oxidative stress. Ann Nutr Metab ; $1 \cdot: Y V_{-}$ r.

Dacie, A. and Lewis, J. ( $(99 \wedge)$ : Piratical Hematology. Churchill Livigstone. New York. Pp. 0.-70.

Denise C., Margot A., Frances M., Chris L. , Jacelyn M., Mark W., Lesley M. and Marlena C. $(r+1\})$ : Consumption of gold kiwifruit reduces severity and duration of selectedupper respiratory tract infection symptoms and increases plasma vitamin $\mathrm{C}$ concentration in healthy older adults. British Journal of Nutrition, $1 \cdot 1,1$ r r $\left.0_{-}\right)$r $\leq 0$.

Dhar S., Tangpong J., Chaiswing L., Oberley T., Clair K. $(\uparrow+11)$ : Manganese superoxide dismutase is a $\mathrm{p}^{\circ \mathrm{r}}$-regulated gene that switches cancers between early and advanced stages. Cancer Res. VI: $74 \wedge \varepsilon-90$.

Donno,D.; Beccaro,G.; Mellano,M.; Canterino,S.; Cerutti,A and Bounous, G. $(r \cdot 1 r)$ : Improving the nutritional value of $\mathrm{Ki}$ wifruit with the application of agroindustry waste extracts. Journal of Applied Botany and Food Quality; $17: 11-10$. 


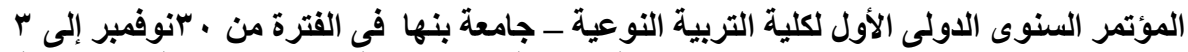

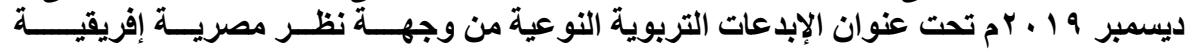

Drabkin, D. ( $19 \leqslant 9)$ : The standardization of Heamoglobin measurements. Am. J. Med. Sci., Y ( ( $): \vee) \cdot$.

Draper, H. and Hadley, M., ( $(9 ৭ \cdot)$ : Malondialdehyde determina-

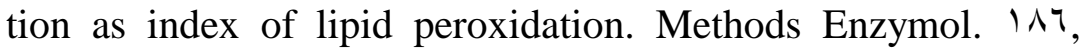
\& $1-\varepsilon r)$.

Duran,M. ;Pedresci, F.; Moyano, P. and Troncoso, E. ( $\uparrow \cdots \vee$ ): Oil partition in pre-treated potato slice during frying and cooling. J. Food Eng., $\wedge$ I: YOV_r ro.

Fayed,O.; Ghada,S.; Mahmoud,I. and Romeilah,R. $(\uparrow+1 \cdot)$ : Protective Effects of Chitosan, Ascorbic Acid and Gymnema Sylvestre Against Hypercholesterolemia in Male Rats. Australian

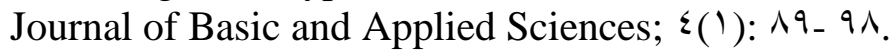

Ferguson AR \& Ferguson LR $(r \ldots r)$ Are kiwifruit really good for you? Acta Hortic $71 \cdot, 1 \% 1-1 \%$.

Fossati, P.; Prencipe, L. and Berti, G. ( $19 \wedge \cdot$ ): Enzymatic colorimetric method of determination of uric acid in serum. Clin. Chem; Yr (r): YrV - rVr.

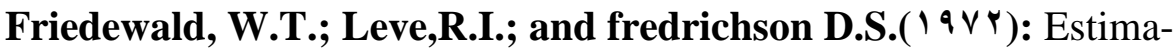
tion of concentration of low-density lipoproteins separated by three different. lin. Clem; $1 \wedge: \leqslant 9 ৭_{-} .{ }_{\text {Y }}$.

Fulgoni, V.; Dreher,M. and Davenport,A. $(r+1 r)$ : Avocado consumption is associated with better diet quality and nutrient intake, and lower metabolic syndrome risk in US adults: results from the National Health and Nutrition Examination Survey

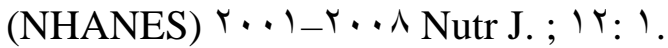

González C., Rosselló M., Simal S., Garau M. , López F., and Femenia, A. $(r \cdot 1 \cdot)$ : Physico-chemical properties of cell wall materials obtained from ten grape varieties and their byproducts: grape pomaces and stems. LWT-Food Science and Technology, $\leqslant r(1 \cdot), 101 \cdot-1014$.

Goupy,p .; Hugues .; M.,Biovin ,p. and Amiot,M.J. ( 19 १ १): Antioxidant composition and activity of barley (Hordeum vulgare) 


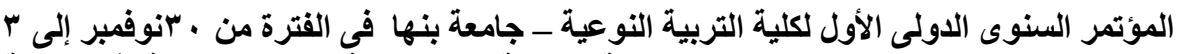

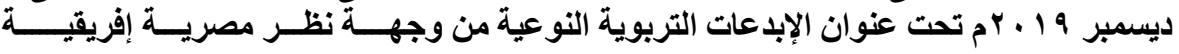

and malt extracts and of isolated phenolic compounds .J. Sci .Food Agric; $\vee 9: 17 r 0_{-} 17 r \varepsilon$.

Hansen P., Marckmann L., Dragsted O., I -L Finné N., Nielsen E. and Grønbæk M. $(\uparrow \ldots \bullet)$ :Effect of red wine and red grape extract on blood lipids, haemostatic factors, and other risk factors for cardiovascular disease. Original Communication. European Journal of Clinical Nutrition $09, \leq \leqslant q_{-} \leqslant 00$.

Henry, R. ( $9 \vee \varepsilon$ ): Creatinine measurement with colorimetric method. In clinical Chem., Principles and technics. Second edition, Haper and Row puplishers. hepatocytes. Cancer Lett, $9 \vee: ~ 7)$. TV.

Horwitz,w. and Latimer,G. ( $r \cdots \vee$ ): Official methods of analysis of AOAC international ;Volume I and II, $\backslash \wedge$ th Edition, Rev $r$.

Imeh U.and Khokhar S. $(r \ldots r)$. Distribution of conjugated and free phenols in fruits: Antioxidant activity and cultivar variations. $\mathbf{J}$ Agric Food Chem; 0・: $7 r \cdot 1,7 r \cdot 7$.

Imran M. , Muhammad R., Abdur N., Muhammad \& Ahmad, Zulfiqar \& Atif, Muhammad \& Awais, Muhammad \& Sami, Muhammad \& Fatima, Zareen \& Waqar, Ahmed. $(Y \cdot \mid V)$. Health Benefits of Grapes Polyphenols. Journal of Environmental and Agricultural Sciences rr|r_⿲丿rq. $1 \cdot\left\{\varepsilon_{-} 01\right.$.

Inory, M. C. ( $190 \leqslant)$ : A micro heamatocrit for determinating the packed cell and heamoglobin concentration on capillary blood. J. Clin. Path., v:rr.

Iwasawa, H.; Morita,E.; Yui,S. and Yamazaki,M. $(Y+11)$ : Antioxidant effects of Kiwifruit in vitro and in vivo. Biol Pharm Bull. $r \varepsilon(1)$ : $\left|r \Lambda_{-}\right| r \varepsilon$.

Jimenez L., and Cederbaum A. $(Y \cdots \varepsilon)$ : Green tea polyphenol epigallocatechin-r-gallate protects hepg ${ }^{r}$ cells against CYPrE ${ }^{r}$ dependent toxicity. Free Radic. Biol. Med ;rч.r०q_rv.

Kasdallah A., Mornagui B., Aouani E., Hammami M., El May M., Gharbi N., Kamoun A., El-Fazaa S. ( $\uparrow \ldots \vee$ ): Resveratrol, 


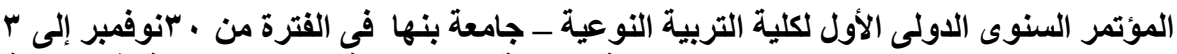

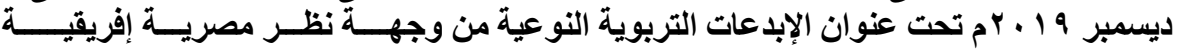

a red wine polyphenol, attenuates ethanol-induced oxidative stress in rat liver. Life Sci $; \wedge \cdot:) \cdot r r+1 \cdot r q$.

Kim, D. and Lee, C.Y. ( $r \ldots \bullet)$ : Extraction and isolation of phenolics. In: Handbook of food analytical chemistry: Pigments, colorants, flavors, texture, and bioactive food components (edited by R.E. Wrolstad, T.E. Acree, E.A. Decker, M.H. Penner, D.S. Reid, S.J. Schwartz, C.F. Shoemaker, D. Smith and P. Sporns) . New Jersey: John Wiley \& Sons, Inc: P. $\leqslant \vee\urcorner$.

kopparapu, N. $(r+11)$ : Miracle nutrient/international journal of pharmacy and technology. $r,(r): 11 \leqslant \cdot-117 \leqslant$.

Liu S., Hou W., Yao P., Zhang B., Sun S., Nussler A.K., Liu L. $\left(Y \cdot \mathcal{P}^{\circ}\right)$ : Quercetin protects against ethanol-induced oxidative damage in rat primary hepatocytes. Toxicol. in Vitro. r. $\cdot ; r \leqslant: 01 r_{-0 Y r}$.

Lopesvirella, M.F.; Stone, S. and Collwellm, J. A. ( $१$ १ V )): Cholesterol determination in high density lipoproteins separated by

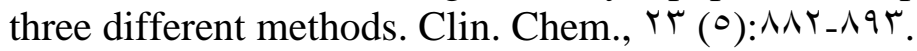

Ludwig D.S. $(r \ldots r)$ : The glycemic index: physiological mechanisms relating to obesity, diabetes, and cardiovascular disease. JAMA; $r \wedge v: r \leq 1 \leq-r r$.

Makni, M.; Fetoui, N.; Gargouri, H.; Jaber, T.; Boudawar, A. and Zeghal, N. $(r \ldots \wedge)$ : Hypolipidemic and hepatoprotective effects of flaxseed and pumpkin seed mixture in $\omega^{-\Gamma}$ and $\omega^{-\tau}$ fatty acids in hypercholesterolemic rats. Food Chem. Toxicol; ¿T: MVI $\leqslant-T V Y \cdot$.

Maria L., Iwona J., Hanna L., Yong-S., Jacek N. Adamo D. , Moshe W. and Shela G. $(r+1 r)$ : Health-Promoting Effects of Ethylene-Treated Kiwifruit 'Hayward'from Conventional and Organic Crops in Rats Fed an Atherogenic Diet. J. Agric. Food

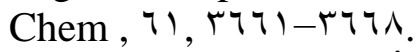

Moreno,A.; Navarro,M. Álvarez,L.;Cevallos,G. and Ortega,M. $(Y \cdots V)$ : comparative study of the hypolipidemic effect induced 


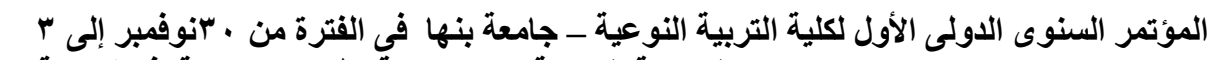

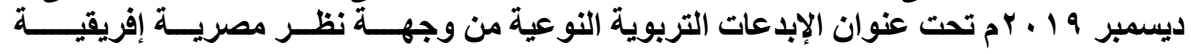

by different monounsaturated Avocado oils. Viña Del Mar,

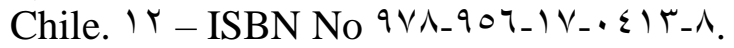

Mukherjee S., Das S.K., Vasudevan D.M. $(r+1 r)$ : Dietary grapes (Vitis vinifera) feeding attenuates ethanol-induced oxidative stress in blood and modulates immune functions in mice. Indian

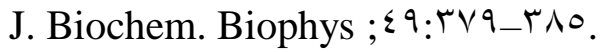

Naveh,E.; Werman,M.; Sabo,E. and Neeman,I. ( $\left.r^{+} \mid r\right)$ : Defatted Avocado Pulp Reduces Body Weight and Total Hepatic Fat But Increases Plasma Cholesterol in Male Rats Fed Diets with Cholesterol. J.nutrition.org.

Nishikimi, M. , Appaji, N. and Yagi, K. ( $9 \vee r)$ : The occurrence of superoxide anion in the reaction of reduced phenazine methosulphate and molecular oxygen. Biochem. Biophys. Res. Commun.; $\leqslant \uparrow(r): \wedge \leq q \_\wedge 0 \leqslant$.

Noh J., Kim Y., Gang G., Hwang J., Lee H., Ly S., Oh W., Song K., Lee, C. $(r+11)$ : Hepatoprotective effects of chestnut (Castanea crenata) inner shell extract against chronic ethanolinduced oxidative stress in $\mathrm{C}^{\circ} \mathrm{V} \mathrm{BL} / 7$ mice. Food Chem. Toxicol $; \leqslant 9: 10 r V-10 \leqslant r$.

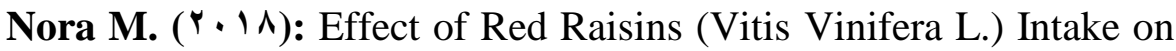
the Level of Some Hematological Tests in a Group of Female Volunteers. Biomed J Sci \& Tech Res $r(r)$.

Papa L., Hahn M., Marsh E., Evans B., Germain D. $\left(\varphi_{+} \mid \leqslant\right)$: SOD $^{r}$ to SOD' switch in breast cancer. $J$ Biol Chem. r. $) \leqslant ; Y \wedge 9: 0 \leqslant 1 Y-\tau$.

Pincemail,J.; Vanbelle,S.; Degrune,F.; Bien,J. and Charlier,C. $(Y \cdot 1)$ : Lifestyle Behaviours and Plasma Vitamin $C$ and $\beta-$ Carotene Levels from the ELAN Population (Li`ege, Belgium). Journal of Nutrition and Metabolism Volume , Article ID $\leq 9 \leq r v \cdot, 1 \cdot$ pages. 


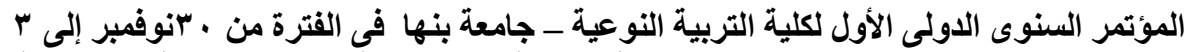

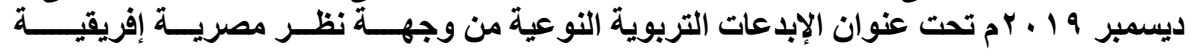

Politeo,O.; Jukic,M. and Miles,M. ( $\uparrow \ldots$ × ฯ): Chemical composition and antioxidant activity of essential oils of twelve spice plans:croat.chem.acta $; \vee q_{:} \leqslant$. or $0_{-} 0 \leqslant 0$.

Reeves, P.; Nielsen, F. and Fahey, G. ( 199 r Ain- 9 r purified diets for laboratory rodents: final report of the american institute of nutrition adhoc writing committee on the reformulation of the ain- $V{ }^{\prime}$ a rodent diet J Nutr. Nov; I r ( ( I I): 1949 _ 1901.

Renée W., Jinny W., Richard B., Alan H., Blair L., Paula S., Chris F., Elizabeth F., Angie A., Lizzie J., Gerald W. Tannock, and Anitra C. $(r \cdot 1 \wedge)$ : Sun Gold Kiwifruit Supplementation of Individuals with Prediabetes Alters Gut Microbiota and Improves Vitamin C Status, Anthropometric and Clinical Markers. Nutrients; $1 \cdot(\mathrm{\vee}): \wedge 90$

Rodriguez,P.; Rodríguez,L.; Zaragoza,E.; Hara,T. and Savín,T. $(r, \mid r)$ : Antioxidant Substances and Trace Element Content in Macroalgae from a Subtropical Lagoon in the West Coast of the Baja California Peninsula. Vitam Trace Elem $r: 1 \cdot \wedge$.

Rush E., Patel M., and Plank L. $(r \ldots r)$ : Kiwifruit promotes laxation in the elderly. Asia Pac J Clin Nutr $11,17 \varepsilon_{-} 171$.

Salem A. and Saltana H. $(r \cdot \mid \bullet)$ : Chemical composition op pulp, seed and peel or red grape fromlibya.. GJSR Journal. $r(r), \tau_{-}$ 11, E-ISSN: rrII-VrrX.

Shivraj H., Kim S., Eun Y., and Park S. $\left(\Upsilon_{\cdot} \mid r\right)$ : Polyphenolic Contents and Antioxidant Properties of Different Grape (V. vinifera, V. labrusca, and V. hybrid) Cultivars. BioMed Research International $\vee \wedge \wedge .70,0$.

Singletary,A. $(r+1 r)$ : Kiwifruit Overview of Potential Health Benefits Nutrition Today; $r \mathrm{~V}(\varepsilon \vee)$

Snedecor, G. and Cochran, W. ( $१ \uparrow \wedge \cdot)$ : Statistical methods., ${ }^{\text {th }}$ Ed., Iowa State University Press, Ames, USA ( $\left.q^{\circ}\right)$.

Solanki,Y. and Bhatt,R. ( $(\cdot \mathcal{P} \cdot)$ : Effects of antioxidant vitamins along with atorvastatin and atorvastatin-niacin combination on 


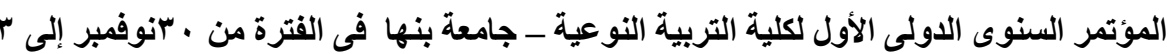

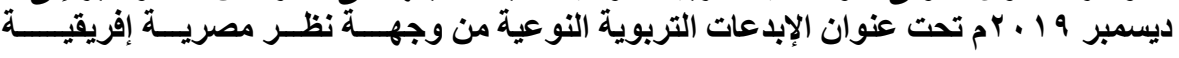

diet-induced hypercholesterolemia in rats. Int J Physiol Pathophysiol Pharmacol ; $r(1): 0 V_{-}-7$ r.

Stanley, J. $(r \cdots \vee)$ : the implications of recent research on trans fatty acids. Lipid Technol. ( 19$): 17_{-} / \mathrm{V}$.

Takeoka, G.R. and Dao, L.T. ( $\uparrow \ldots r)$ : Antioxidant constituent of almond [Ptunus dulicis (Mill) D.A. Web.] hulls. J Agric Food Chem. 01: $\left\{97 \_0.1\right.$.

Title L., Cummings P., Giddens K., Nassar A. ( $\uparrow \ldots$. . ): Oral glucose loading acutely attenuates endothelium-dependent vasodilation in healthy adults without diabetes: an effect prevented by vitamins $\mathrm{C}$ and E. J Am Coll Cardiol ; $r \tau_{\text {: }} r$ ) $\left.10_{-} q\right)$.

Venter,A. $(r \cdot 1 r)$ : Phenolic composition and in vitro antioxidant capacity of South African plums (prunus salicina lindl). Stellenbosch University http://scholar.sun.ac.za $1-11 \mathrm{~V}$.

Zeeuw D., Remuzzi G., Parving H., Keane F., Zhang Z., and Shahinfar S. $(r \ldots \varepsilon)$ : Proteinuria, a target for renoprotection in patients with type $r$ diabetic nephropathy: lessons from RENAAL. Kidney Int ; $70: r r \cdot 9-r r r$. 